\title{
Morphometric and neurochemical characterization of primary sensory neurons expressing the insulin receptor in the rat
}

\author{
Ph.D. Thesis
}

Bence András Lázár M.D.

\author{
Supervisors: \\ Prof. Dr. Gábor Jancsó M.D. Ph.D. D.Sc. \\ Dr. Péter Sántha M.D. Ph.D. Dr. med. habil \\ Doctoral School of Theoretical Medicine \\ Department of Physiology \\ Department of Psychiatry \\ Faculty of Medicine \\ University of Szeged
}

Szeged

2019 
Original research articles related to the Thesis:

I. Lázár BA, Jancsó G, Horváth V, Nagy I, Sántha P. The Insulin Receptor is Differentially Expressed on Somatic and Visceral Primary Sensory Neurons. Cell and Tissue Res. 374:243-249. 2018

\section{IF: 3.043}

II. Lázár BA, Jancsó G, Oszlács O, Nagy I, Sántha P. The Insulin Receptor is Colocalized With The TRPV1 Nociceptive Ion Channel and Neuropeptides in Pancreatic Spinal and Vagal Primary Sensory Neurons. Pancreas. 47:110-115. 2018

\section{IF: 2.958}

Cumulative impact factor of the original research articles related to the Thesis: 6.001

\section{Original research articles not closely related to the Thesis:}

I. Lázár BA, Jancsó G, Pálvölgyi L, Dobos I, Nagy I, Sántha P. Insulin Confers Differing Effects on Neurite Outgrowth in Separate Populations of Cultured Dorsal Root Ganglion Neurons: The Role of The Insulin Receptor. Frontiers in Neurosci. 12:732. 2018

IF: 3.877

Cumulative impact factor of the original research articles not closely related to the Thesis: 3.877

Total impact factor: 9.878 
ABBREVIATIONS

1. INTRODUCTION

1.1 Primary sensory neurons: the eminent players of somatovisceral functions 6

1.1.1. Morphological and functional classification of primary sensory neurons 7

1.1.2. Basic functional morphology and neurochemical traits of C-fibre primary sensory neurons

1.1.3. Capsaicin: a specific chemical tool in the study of nociceptive primary sensory neurons

1.2. Insulin and its possible role in the modulation of the function of TRPV1-expressing primary sensory neurons.

1.3. The role of nociceptive primary sensory nerves in pathological conditions

1.4. Retrograde axonal tract tracing methods for the identification of primary sensory neurons innervating specific organs

2. AIMS OF THE STUDY

3. MATERIALS AND METHODS

3.1. Experimental animals

3.2. Surgery and retrograde neuronal labelling 24

3.3. Histological methods 24

3.3.1. Tissue preparation and sectioning 24

3.3.2. Lectin- and immunohistochemistry 25

3.4. Data analysis 25 
4.1. Retrograde labelling of DRG and NG neurons innervating somatic (skin, muscle) and visceral (urinary bladder, pancreas) organs

4.2. Expression of TRPV1 in identified somatic and visceral primary sensory neurons ..... 28

4.3. InsR expression in retrogradely labelled dorsal root ganglion and nodose ganglion neurons innervating the skin, skeletal muscle, the pancreas and the urinary bladder

4.4. Co-localization of the InsR with the TRPV1 in retrogradely labelled somatic and visceral dorsal root ganglion and nodose ganglion neurons

4.5. Co-localization of the InsR with sensory neuropeptides (substance $\mathrm{P}$ and calcitonin gene-related peptide) in pancreatic dorsal root ganglion and nodose ganglion neurons ...... 35

5. DISCUSSION

6. CONCLUSIONS 46

7. SUMMARY 47

8. ACKNOWLEDGEMENTS 49

9. REFERENCES 50 


\section{ABBREVIATIONS}

Akt: protein kinase B

bWGA: biotin-conjugated wheat germ agglutinin

CaMkII: $\mathrm{Ca}^{2+} /$ calmodulin dependent kinase II

CGRP: calcitonin gene-related peptide

CNS: central nervous system

DRG: dorsal root ganglion

ERK: extracellular signal regulated kinases

FRAP: fluoride-resistant acid phosphatase

G-protein: guanyl nucleotide-binding protein

GDNF: glial cell line-derived neurotrophic factor

GRB2: growth factor receptor bound protein 2

HRP: horseradish peroxidase

IB4: isolectin B4

IGF-1: insulin-like growth factor 1

InsR: insulin receptor

IR: immunoreactive

IRS: insulin receptor substrate

MAPK: mitogen activated protein kinase

NK1R: neurokinin-1 receptor

NG: nodose ganglion

NGF: nerve growth factor

PI3K: phosphatidylinositol-3 kinase

PiP2: phosphatidylinositol diphosphate

PKA: protein kinase A

PKC: protein kinase $\mathrm{C}$

PLC: phospholipase C 
PSN: primary sensory neuron

RTX: resiniferatoxin

SOS: son of sevenless protein

SP: substance P

TMP: thiamine monophosphatase

TRPV1: transient receptor potential vanilloid 1 receptor

WGA: wheat germ agglutinin 


\section{INTRODUCTION}

1.1 Primary sensory neurons: the eminent players of somatovisceral functions

In 1908, Sir Henry Head and William Halse Rivers have published their findings on the classification of sensations. At St. John's College, Cambridge, J. Sherren has divided the cutaneous branch of the radial nerve of Head by his persuasion to map the sensory loss caused by nerve injury and the restoration of function by the regeneration of the nerve. Head has observed that there are three disparate forms of sensations: deep, epicritic and protopathic sensibilities. He suggested that protopathic sensibility involves sensations evoked by painful pressure and thermal stimuli, whereas epicritic sensibility subserves fine and discriminative touch sensations (Head et al., 1905; Rivers and Head, 1908). Later, it has been revealed that there exist two anatomically, morphologically and functionally disparate pathways for epicritic and protopathic sensibility: the medial lemniscus pathway and the spinothalamic pathway and their trigeminal counterparts: the dorsal and the ventral trigeminal lemniscus pathways. Further, there are two anatomically and functionally different pathways which detect stimuli originating from the body surface and the musculoskeletal system (somatic sensory system), and the visceral organs (viscerosensory system), respectively.

The cell bodies of the pseudo-unipolar neurons, the key players and the first-order neurons of somato- and viscerosensory pathways, are localised in the dorsal root ganglia (DRGs), and in the sensory ganglia of the $\mathrm{V}^{\text {th }}$, VII ${ }^{\text {th }}$, IX ${ }^{\text {th }}$ and $\mathrm{X}^{\text {th }}$ cranial nerves. Somatic and visceral primary sensory neurons (PSNs) possess central and peripheral axonal branches and are involved, inter alia, in the detection of nociceptive/painful stimuli. The peripheral branches of different classes of PSNs end in specific sensory nerve endings which detect non-noxious mechanical and thermal stimuli and noxious/painful mechanical, chemical and thermal stimuli originating in the skin, the musculoskeletal system and the visceral organs. The central branches of PSNs project to the central nervous system (CNS) via the dorsal (sensory) roots of spinal and cranial nerves. The axons of the second-order neurons cross over in the ventral white commissure of the spinal cord and ascend via the lateral or the ventral spinothalamic tract. However, ascending visceral pathways include other tracts such as the dorsal columns, the spinoreticular, spinomesencephalic and spinoparabrachial tracts. Nevertheless, the cranial sensory axons of the second-order neurons located in the spinal trigeminal nucleus cross over in the medulla oblongata and comprise the ventral trigeminal lemniscus pathways. 
Third-order neurons of distinct functional properties are located and segregated in the specific nuclei of the thalamus. For example, fibres which convey visceral sensory information are synapsing with neurons in the parafascicular nucleus, whereas neurons transmitting nociceptive information from the body surface are synapsing with neurons in the ventral posterolateral nucleus and the medial thalamic nuclei. Thalamic neurons project to the primary somatosensory cortex, although other cortical areas, such as the insular cortex are also involved.

\subsubsection{Morphological and functional classification of primary sensory neurons}

Based on the findings of Head and Rivers (1908), Gasser and Erlanger (1927) showed that PSNs in spinal and cranial sensory ganglia can be classified into three main categories: neurons with fast conducting myelinated A- and B-fibres and neurons with slowly-conducting unmyelinated, C-fibres (Gasser and Erlanger, 1927). Fibres of type A are frequently subdivided into A $\alpha, A \beta$ and $A \delta$-fibres based on their different conduction velocities. Besides this classification, Lloyd and Hunt proposed a slightly different categorization by studying reflex activities in animals. They classified sensory nerve fibres into four size-groups by their diameters: type I-fibres which are equivalent to the myelinated A $\alpha$-fibres, type II-fibres identical with cutaneous afferent myelinated A $\beta$-fibres, type III-fibres and type IV-fibres representing the myelinated A $\delta$ and unmyelinated C-fibres, respectively (Lloyd, 1943; Hunt, 1951) (Table 1).

Morphologically spinal and cranial sensory ganglion neurons can be divided into two main categories: type A or large light neurons and type B or small dark neurons (Andres, 1961; Lawson and Biscoe, 1979; Lawson et al., 1984). This classification is based on ontogenetic, neurochemical and morphological properties (Lawson and Biscoe, 1979). Immunohistochemical and electron microscopic findings have also revealed that A-type PSNs are rich in neurofilaments and contain distinctly organized accumulation of cisterns of rough endoplasmic reticulum (Nissl bodies), while type B neurons contain few neurofilaments and less organized rough endoplasmic reticulum. By using anti-neurofilament antibodies, it has also been demonstrated that type A neurons show intense immunohistochemical staining for the 200 $\mathrm{kDa}$ neurofilament subunit, whereas type B neurons show immunohistochemical staining for the $66 \mathrm{kDa}$ neurofilament subunit peripherin (Lawson et al., 1984; Lawson and Waddell, 1991; Sann et al., 1995). Neurofilament-rich, large-sized type A neurons have myelinated A $\alpha-$, A $\beta$ or A $\delta$-fibres, whereas neurofilament-poor, small-sized type B neurons give rise to unmyelinated C-fibres (Lawson et al., 1984) (Table 1). 


\begin{tabular}{|c|c|c|c|c|c|}
\hline $\begin{array}{c}\text { Lloyd-Hunt } \\
\text { classification }\end{array}$ & $\begin{array}{c}\text { Gasser-Erlanger } \\
\text { classification }\end{array}$ & $\begin{array}{c}\text { Diameter } \\
(\mu \mathrm{m})\end{array}$ & $\begin{array}{c}\text { Conduction } \\
\text { velocity } \\
(\mathrm{m} / \mathrm{s})\end{array}$ & Myelin & $\begin{array}{c}\text { Neurofilament } \\
\text { content }\end{array}$ \\
\hline Ia & A $\alpha$ & $13-20$ & $80-120$ & yes & $\begin{array}{c}200 \mathrm{kDa} \\
\text { (type A) }\end{array}$ \\
\hline Ib & A $\alpha$ & $13-20$ & $80-120$ & yes & $\begin{array}{l}\text { 200 kDa } \\
\text { (type A) }\end{array}$ \\
\hline II & A $\beta$ & $6-12$ & $33-75$ & yes & $200 \mathrm{kDa}$ \\
(type A)
\end{tabular}

Table 1. Classification of primary sensory neurons by morphological and functional properties

Functionally, PSNs can be divided into two main categories: first, PSNs which transmit nonnoxious mechanical and thermal stimuli and largely correspond to type A PSNs with large and thinly myelinated axons. The other category is comprised of nociceptive PSNs, which transmit impulses evoked by noxious mechanical, thermal and chemical stimuli and are comprised largely of type B PSNs. The subject matter of this Thesis is confined largely to investigations into the morphological and neurochemical characteristics of nociceptive PSNs. Therefore, in the next chapter, the morphological, functional and neurochemical properties of nociceptive PSNs will be described in some detail.

1.1.2. Basic functional morphology and neurochemical traits of C-fibre primary sensory neurons

Sensation of pain elicited by noxious mechanical, chemical or thermal stimulation of the skin, the musculoskeletal system and the visceral organs are detected by nociceptors. The term, nociceptor was introduced by Sherrington who described nociceptors as a special type of PSNs with differing sensitivities and thresholds for painful stimuli that distinguish them from other classes of sensory neurons (Sherrington, 1906). Morphologically, nociceptors are of two types: myelinated $\mathrm{A} \delta$ and $\mathrm{A} \beta$-fibre nociceptors, and unmyelinated C-fibre nociceptors (Djouhri and 
Lawson, 2004). C-fibres can be classified on the basis of their sensitivity to different stimuli: polymodal nociceptors, which are sensitive to mechanical, chemical and thermal stimuli and the C-mechanoinsensitive afferents (Beck and Handwerker, 1974; LaMotte and Campbell, 1978; Meyer and Campbell, 1981).

Besides the morphological differences between disparate sub-classes of nociceptors, C-fibre PSNs can be classified by other neurochemical and functional properties. Earlier studies have revealed that C-fibre PSNs can be divided into two neurochemically and functionally distinct subpopulations: peptidergic and non-peptidergic neurons (Hökfelt et al., 1975; Price, 1985; Silverman and Kruger, 1988; Silos-Santiago et al., 1995; Bennett et al., 1998; Snider and McMahon, 1998). Histochemical studies have demonstrated that about 30-50\% of smallmedium sized DRG neurons express the enzyme fluoride-resistant acid phosphatase (FRAP) identical with neurons expressing thiamine monophosphatase (TMP, Inomata and Ogawa, 1981; Knyihar-Csillik et al., 1986; Silverman and Kruger, 1990). It has also been revealed that practically all FRAP/TMP-positive sensory ganglion neurons are nociceptive in nature (Jancsó and Knyihár, 1975; Jancsó, 1992). TMP activity has also been demonstrated in the substantia gelatinosa Rolandi of the spinal dorsal horn, and in its trigeminal counterpart, the subnucleus gelatinosus of the spinal trigeminal nucleus (Jancsó and Knyihár, 1975; Jancsó and Király, 1980; Jancsó et al., 1985). Recently, FRAP/TMP has been identified as the enzyme prostatic acid phosphatase (Taylor-Blake and Zylka, 2010).

It has been demonstrated that many non-peptidergic neurons bind isolectin B4 (IB4), the lectin of the plant Griffonia simplicifolia (Bandeiraea simplicifolia) which has a high affinity for terminal $\alpha$-galactosyl residues expressed by various cells including DRG neurons. IB4-binding C-fibre PSNs do not or rarely contain neuropeptides (Silverman and Kruger, 1990; Alvarez and Fyffe, 2000).

The findings of Nikolaus (Miklós) Jancsó demonstrated that release of vasoactive substances from peripheral sensory nerve endings have a pivotal role in the mediation of neurogenic inflammatory responses (later termed the sensory efferent or local regulatory functions; cf. Jancsó et al., 2009). Early studies by Pavao Stern and his colleagues (Gasparovic et al., 1964) using bioassay techniques suggested that nociceptive C-fibre PSNs which mediate neurogenic inflammatory responses may contain peptides, such as substance P (SP). It is now well established that local vascular reactions mediated by nociceptive sensory nerves are effected by the release of various neuropeptides such as calcitonin gene-related peptide (CGRP) and SP (Gamse et al., 1980, 1987; Jancsó et al., 1985; Jancsó et al., 1987; Holzer, 1988; Maggi and 
Meli, 1988; Szolcsányi, 1996). Although immunohistochemical studies have revealed that peptide-containing neurons comprise a unique population of small-medium sized C-fibre afferent neurons (Price, 1985), CGRP is also expressed by medium and large-diameter neurons (Ju et al., 1987). However, besides SP and CGRP, the two characteristic markers of peptidergic PSNs, other neuropeptides, such as galanin, cholecystokinin, vasoactive intestinal polypeptide, somatostatin, neurokinin $\mathrm{A}$ and pituitary adenylate cyclase-activating peptide are also expressed by C-fibre PSNs (Jancsó et al., 1981; Ju et al., 1987; Lazarov, 2002).

CGRP was discovered by the analysis of the mRNA of calcitonin in the thyroid glands and hypothalamus of the rat. It has been shown that CGRP is widely expressed in neural tissues (Amara et al., 1982). After its discovery, it has been revealed that capsaicin induces CGRP release from sensory nerves endings, and CGRP is primarily localized to C and A $\delta$ sensory fibres (Maggi, 1995). CGRP has a potent vasodilator activity (Brain et al., 1985) and contributes to neurogenic inflammation (for a historical review see Sousa-Valente and Brain, 2018). CGRPcontaining PSNs play a crucial role in several pathological processes such as vascular and inflammatory reactions in somatic and visceral tissues (Holzer, 1988; Maggi and Meli, 1988; Dux et al., 2003; Birder and Kullmann, 2018; Jaromi et al., 2018; Sousa-Valente and Brain, 2018).

SP is an 11-amino acid peptide belonging to the tachykinin peptide family. It has been discovered in gut extracts by U. S. v. Euler and J. H. Gaddum who identified it as a substance producing intestinal contraction (Euler and Gaddum, 1931). Later, it has been revealed that SP is abundant both in the periphery and in the CNS. SP is present in PSNs and in the spinal cord dorsal horn and is functionally related to nociception (Duggan et al., 1987). Moreover, SP results in plasma extravasation and has a potent vasodilator effect (Bossaller et al., 1992), thus, it is involved in local inflammatory processes, including neurogenic inflammation, and acts as a pro-inflammatory agent. SP is exclusively expressed by small-sized C-fibre PSNs which are sensitive to capsaicin (Hökfelt et al., 1975; Jancsó et al., 1981).

Besides their different neuro(histo)chemical properties, peptidergic and non-peptidergic C-fibre PSNs have distinct developmental features, including their differential responsiveness to neurotrophins (Johnson et al., 1986). Silos-Santiago and his colleagues have revealed that nociceptive embryonic DRG neurons express the tyrosine kinase A (TrkA), the receptor for the nerve growth factor (NGF), and require NGF for survival (Silos-Santiago et al., 1995). However, the trophic factor sensitivity of rodent DRG neurons changes during the early 
postnatal period. About 40-50\% of small-sized sensory neurons lose their sensitivity to NGF and lack TrkA expression. These DRG neurons express TMP/FRAP and bind the lectin IB4. The other sub-class of DRG neurons which are still sensitive to NGF and express TrkA, contain neuropeptides such as CGRP and SP (Silos-Santiago et al., 1995). Non-peptidergic sensory neurons become sensitive to glial cell line-derived neurotrophic factor (GDNF) and express another receptor tyrosine kinase, Ret (Molliver et al., 1997; Bennett et al., 1998).

In summary, adult peptidergic PSNs are sensitive to NGF, express TrkA and co-express CGRP and SP, whereas the non-peptidergic sub-class of nociceptive sensory neurons are sensitive to GDNF, express RET, and co-express TMP/FRAP and bind the IB4 (Table 2). These two different sub-classes of B-type small to medium sized DRG neurons are nociceptive in function, and have a selective chemosensitivity for exogenous pungent agents, such as capsaicin and resiniferatoxin (RTX). The knowledge of the specific neurochemical features of nociceptive PSNs enables their morphological identification by using histochemical and immunohistochemical techniques of high sensitivity and specificity.

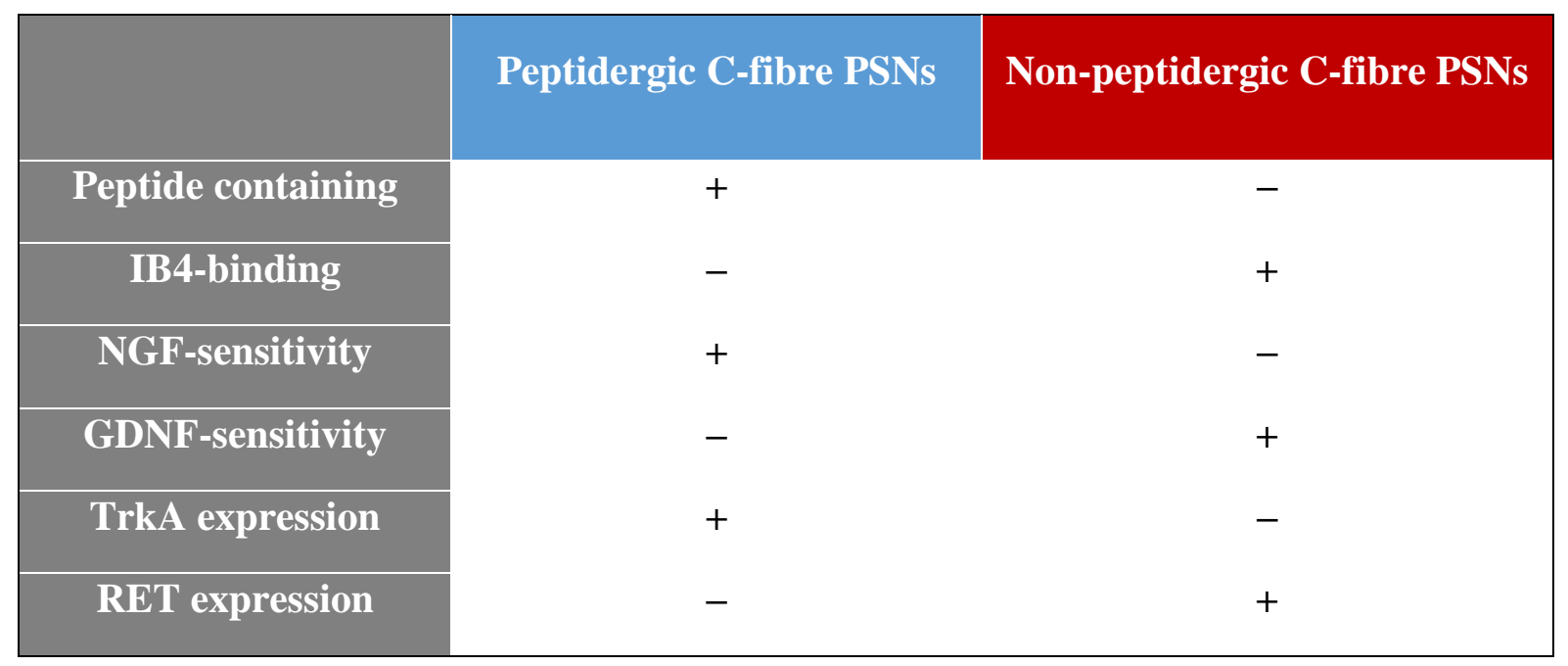

Table 2. Neurochemical traits of sub-classes of adult C-fibre DRG neurons

1.1.3. Capsaicin: a specific chemical tool in the study of nociceptive primary sensory neurons

Capsaicin is the main, active, highly pungent constituent of chilli peppers which belongs to the genus Capsicum. Chemically, capsaicin is a naturally occurring alkaloid, a derivative of vanillyl amide, 8-methyl-N-vanillyl-6-nonenamide. It is now well-known that it evokes a burning pain sensation and, following repeated local or systemic applications, produces long-lasting unresponsiveness of the skin or mucous membranes to noxious chemical stimuli (Jancsó, 1960, 1968). Allegedly, this effect of chillies has been exploited by Aztecs and Inca's for controlling 
burning pain. Christopher Friedrich Bucholz was the first who extracted capsaicin in impure form in 1816 (Bucholz, 1816). Later, the Hungarian scientist, Endre Högyes suggested that the irritant effect of Capsicum extracts is mediated by sensory nerves (Högyes, 1878). Lastly, the chemical structure of capsaicin has been determined by E.K. Nelson and L.E. Dawson in 1923 (Nelson and Dawson, 1923).

In the second half of the $20^{\text {th }}$ century, N. Jancsó discovered that local or systemic administrations of capsaicin at high concentrations produced insensitivity of the experimental animals to painful stimuli induced by chemical irritants, but not by mechanical stimuli. Since then, the term "capsaicin desensitization" is used to describe this phenomenon (Porszász and Jancsó, 1959; Jancsó, 1960, 1968; Jancsó et al., 1967). Jancsó also observed that local application of capsaicin and mustard oil (allyl-isothiocyanate) onto the skin produces not only burning pain, but local vascular reactions such as vasodilation and plasma extravasation in rats. This observation suggested that the role of capsaicin sensitive sensory fibres may be more complex than merely the transmission of nociceptive stimuli. It has been revealed that these nerves have a dual function: on the one hand, they convey nociceptive impulses toward the CNS (sensory afferent function), and on the other hand, they play a crucial role in local vascular responses (sensory efferent or local regulatory function) i.e. in neurogenic inflammation (Jancsó, 1960).

The morphological and additional functional characteristics of capsaicin-sensitive PSNs have been revealed by Gábor Jancsó and his colleagues. Jancsó and his colleagues (1977) have observed that systemic administration of capsaicin to new-born rats results in a selective degeneration of a morphologically, neurochemically and functionally unique sub-class of somatic and visceral PSNs in DRGs and in cranial sensory ganglia (Jancsó et al., 1977). Detailed morphological studies using histological techniques to detect axon terminal degeneration have revealed the CNS distribution of chemosensitive/nociceptive primary afferents in several animal species (Jancsó and Király, 1980). Neonatal capsaicin treatment by producing degeneration of chemosensitive PSNs results in a permanent abolition of the neurogenic inflammatory response (Jancsó et al., 1977; Jancsó et al, 1980). It has also been revealed that capsaicin-sensitive nerves participate in the transmission of impulses evoked by noxious heat (Jancsó et al., 1980, 1987). Making use of the selective neurodegenerative action of capsaicin on chemosensitive PSNs, the morphological, functional and neurochemical characteristics and significance of this unique sub-class of nociceptive PSNs has been revealed. 
In the early 1990s, studies on the effect of RTX in Peter Blumberg's laboratory have provided evidence for the existence of a specific receptor for capsaicin. Szállási and Blumberg have described that a homovanillic acid ester, RTX, the ingredient of Euphorbia resinifera, shows analogy with capsaicin and may be regarded as an ultrapotent analogue of it (Table 3). The binding characteristics of the receptor and its distribution within the nervous system have been described in detail by Árpád Szállási and his colleagues (Szállási and Blumberg, 1990; Szállási et al., 1994). They have suggested that the capsaicin receptor is sensitive to molecules structurally related to vanilloids; henceforth the capsaicin-receptor was named the "vanilloid receptor".

In the late 1990s, Michael J. Caterina and his colleagues have identified an ion channel, which resembled transient receptor potential ion channels discovered in the eye of a mutant fruit fly Drosophila melanogaster. This non-selective cation channel, termed the capsaicin or transient receptor potential vanilloid 1 receptor (TRPV1, Caterina et al., 1997) is specifically sensitive to capsaicin and related compounds, the vanilloids, and is also sensitive to intense heat. Hence, it was the first cloned thermal transducer sensitive molecule to noxious heat $\left(>43{ }^{\circ} \mathrm{C}\right.$ ) (cf. Tominaga et al., 1998). It has also been demonstrated that TRPV1 is selectively expressed in a subset of small-medium sized PSNs (Caterina et al., 1997). By developing TRPV1 knock-out mice, it has also been revealed that TRPV1 has a fundamental role in physiological and pathological processes associated with capsaicin-sensitive sensory nerves. Sequence analysis has revealed that TRPV1 is a member of the TRP receptor superfamily. The TRP receptor superfamily can be divided into seven subfamilies, and comprises more than 30 ion channels (Caterina et al., 1997; Guo et al., 2001; Nilius and Owsianik, 2011). The vanilloid, the ankyrin and the melastatin types are thermosensitive and play an important role in nociceptive transduction and neurogenic inflammation (Holzer, 1991; Uchida and Tominaga, 2011).

The cloned form of the TRPV1 is predicted to have six transmembrane domains with an additional short, intramembrane stretch between the fifth and sixth transmembrane domains (Caterina et al., 1997). The functional form of the receptor consists of a tetramer of subunits. Both the N- and C-termini are localized intracellularly that acquire several regulatory features including various phosphorylation sequences for protein kinase A (PKA), protein kinase C (PKC), $\mathrm{Ca}^{2+} /$ calmodulin dependent kinase II (CaMkII) and for phosphatidylinositol diphosphate (PiP2) (Montell, 2001). The capsaicin-binding site of the receptor is located intracellularly, and the activation by capsaicin or other vanilloids results in the influx of $\mathrm{Ca}^{2+}$ and $\mathrm{Na}^{+}$, thus the depolarization of the cell (Jung et al., 1999). The increase of intracellular $\mathrm{Ca}^{2+}$ 
concentration in DRG neurons, which was shown in histochemical studies first by Jancsó and his colleagues following the administration of capsaicin to new-born rats, has a pivotal role in the exocytosis of neuropeptides from sensory nerve terminals, too (Jancsó et al., 1978). Further, the TRPV1 is permeable for $\mathrm{Co}^{2+}$ ions that has been utilized for in vitro histochemical identification of capsaicin-sensitive neurons (Hogan, 1983).

Under physiological conditions, TRPV1 is activated by noxious heat $\left(\sim 43^{\circ} \mathrm{C}\right)$, low $\mathrm{pH}$, various lipids from the metabolism of arachidonic acid, protons and endogenous vanilloids, such as $\mathrm{N}$ oleoyldopamine, anandamide (arachidonoylethanolamide) and $\mathrm{N}$-arachidonoyl dopamine (Di Marzo et al., 2001; Van Der Stelt and Di Marzo, 2004) (Table 3).

Additionally, TRPV1 can be sensitized by various substances released upon tissue damage and the following inflammation (Julius and Basbaum, 2001). Bradykinin (Tang et al., 2004), histamine (Kim et al., 2004), ATP, prostaglandin E2 (Moriyama et al., 2005) and NGF (Bonnington and McNaughton, 2003) are the well-known agents which sensitize the TRPV1 (Table 3). The molecular mechanisms of the sensitization involve the activation of guanyl nucleotide-binding protein (G-protein)-coupled receptors. G-protein-coupled receptors are connected to different signalling pathways involving PKA, PKC, phosphatidylinositol-3 kinase (PI3K), phospholipase C (PLC) and CaMkII. Moreover, it has been revealed that members of receptor tyrosine kinases such as insulin-like growth factor 1 (IGF-1) and insulin can also sensitize the TRPV1 (Sathianathan et al., 2003; Van Buren et al., 2005; Lilja et al., 2007) (Table $3)$.

1.2. Insulin and its possible role in the modulation of the function of TRPV1-expressing primary sensory neurons

Recently, several studies have suggested that insulin, besides its pivotal role in body metabolism, has potential effects on PSNs. Insulin is the most potent anabolic polypeptide with a molecular mass of about 6000 Da secreted by the $\beta$ cells of the islets of Langerhans in the form of a single chain of three peptides, and is critically involved in the regulation of carbohydrate, lipid and protein metabolism (Docherty and Steiner, 1982; Bliss, 1993). After its discovery in 1922 (Banting and Best, 1922), it has been revealed that under physiological conditions glucose is the most important agent which stimulates the pancreatic secretion of insulin (Chen and Porte, 1976). It is to be noted that in addition to insulin other endogenous factors such as growth hormones, adrenocorticosteroids, catecholamines, sensory 
neuropeptides and neural stimuli may also modulate insulin's secretion (Bliss, 1993). The most important action of insulin is to promote the transport of blood glucose into insulin-dependent tissues such as the liver, muscle and adipose tissue by the regulation of glucose transporters (Bliss, 1993; Furtado et al., 2002).

\begin{tabular}{|c|c|c|}
\hline & Endogenous factors & Exogenous factors \\
\hline Activators & $\begin{array}{c}\text { heat } \\
\text { low } \mathrm{pH} \\
\text { arachidonic acid } \\
\text { N-oleoyldopamine } \\
\text { N-arachidonoyl dopamine }\end{array}$ & $\begin{array}{l}\text { capsaicin } \\
\text { resiniferatoxin } \\
\text { other vanillotoxins }\end{array}$ \\
\hline Inhibitors & $\begin{array}{c}\text { PIP2 } \\
\text { calmodulin }\end{array}$ & $\begin{array}{l}\text { capsazepine } \\
\text { cinnamides } \\
\text { carboxamides }\end{array}$ \\
\hline Sensitizers & $\begin{array}{c}\text { bradykinin } \\
\text { prostaglandins } \\
\text { NGF } \\
\text { histamine } \\
\text { ATP } \\
\text { IGF-1 } \\
\text { insulin }\end{array}$ & $\begin{array}{l}\text { capsaicin } \\
\text { resiniferatoxin } \\
\text { other vanillotoxins }\end{array}$ \\
\hline
\end{tabular}

Table 3. Exogenous and endogenous factors which activate, inhibit or sensitize the TRPV1 nociceptive ion channel

The biological effects of insulin are mediated by the insulin receptor (InsR), one of the first peptide receptor identified decades ago (Massague et al., 1980). The InsR is a heterotetrametric transmembrane receptor which belongs to the tyrosine kinase receptor superfamily. It consists of 2 extracellular $\alpha$ and 2 transmembrane glycoprotein $\beta$ subunits linked by disulphide bonds (Kido et al., 2001). Insulin by binding to the $\alpha$ subunit, induces conformational changes of the intracellular component of the $\beta$ subunit conferring the phosphorylation of tyrosine residues on intracellular substrates such as insulin receptor substrate (IRS) proteins (Saltiel and Pessin, 
2003). Upon phosphorylation, IRS proteins can bind other signalling molecules containing srchomology-2 domain proteins, which include PI3K and growth factor receptor bound protein 2 (GRB2)/son of sevenless (SOS) protein (Waters et al., 1995; White, 2006). IRS proteins show a different tissue distribution and physiological effect, e.g. IRS-1 is the major IRS in the skeletal muscle and involved in the mitogenic effects of insulin, while IRS-2 is responsible for the mediation of growth of $\beta$ cells and peripheral actions of insulin (White, 2006).

Signalling pathways of insulin involves the PI3K and the Grb2/SOS signalling mediators. PI3K increases lipid and protein synthesis and the translocation of glucose transporters by regulating the protein kinase B (Akt) and PKC. Grb2/SOS is linked to the rat sarcoma protein which activates the mitogen activated protein kinase (MAPK)/extracellular signal regulated kinases (ERK) cascades. The MAPK/ERK pathway is related to proliferation and cell growth.

After identification of the InsR, morphological studies focused on its tissue distribution. Earlier studies by using a radiolabelling technique have revealed that InsR exists on the membrane of all mammalian cells, however, with a different distribution pattern (Bergeron et al., 1980; Gammeltoft, 1984; Whitcomb et al., 1985; Watanabe et al., 1992). In vivo studies demonstrated high specific binding of intravenously injected $\mathrm{I}^{25 \mathrm{I}}$-insulin in the liver, the pancreas, the intestines and the blood vessels of the skeletal muscles (Bergeron et al., 1980; Gammeltoft, 1984; Whitcomb et al., 1985; Watanabe et al., 1992).

Several studies by using in vitro autoradiography demonstrated the presence of InsRs in the brain (Baskin et al., 1986; Hill et al., 1986; Werther et al., 1987). Moreover, the presence of the InsR mRNA has also been demonstrated in the rat brain (Marks et al., 1990). Other studies demonstrated the presence of InsRs in the olfactory bulb, cerebellum, hippocampus and in the hypothalamus. These findings have also been supported by immunohistochemical studies demonstrating the localization of InsRs in those brain areas (Havrankova et al., 1978; Pacold and Blackard, 1979).

Besides its pivotal role in the regulation of energy metabolism, insulin has been suggested to exert distinct effects on several neuronal systems. Insulin has been shown to increase uridine and leucine incorporation in cultured DRGs (Levi-Montalcini, 1966; Burnham et al., 1974), and CNS (Raizada et al., 1980). Ornithine decarboxylase activity is also enhanced by insulin in some regions of the CNS (Roger and Fellows, 1980). 
Nevertheless, the first publications about the neural actions of insulin focused on its possible role in trophic processes in the peripheral nervous system. It has been revealed that insulin enhances neurite outgrowth in cultured human neuroblastoma cells in both serum-containing and serum free media (Recio-Pinto and Ishii, 1984). Further, insulin potentiates NGF's action and increases NGF binding in rat pheochromocytoma PC12 cells which share characteristics with nociceptive PSNs (Recio-Pinto et al., 1984). In addition, administration of insulin at physiological concentrations promotes neurite outgrowth in cultured sympathetic and sensory neurons (Recio-Pinto et al., 1986a). Fernyhough and his colleagues have also demonstrated that cultured DRG neurons respond with an increased regenerative growth to insulin (Fernyhough et al., 1993).

Immunohistochemical studies have supported these observations. Sugimoto and his colleagues have revealed by using immunohistochemistry and reverse transcription polymerase chain reaction that InsR is localized to the paranodal axolemma, the terminal Schwann cell loops, the Schmidt-Lantermann incisures and pericytes in rat myelinated peripheral nerve fibres (Sugimoto et al., 2000). It has also been demonstrated that InsR is expressed in small-sized sensory DRG neurons and in lateral lamina $\mathrm{V}$ and in lamina $\mathrm{X}$ of the spinal cord suggesting the role of InsRs and insulin in nociception (Sugimoto et al., 2002).

The mechanisms of the neurotrophic actions of insulin on PSNs may involve several mechanisms, but the pivotal significance of the InsRs was recognized. For example, DRG neurons develop resistance to the neurite outgrowth-promoting effects of micromolar concentrations of insulin through the desensitization of the InsRs and the inhibition of the PI3/Akt pathway (Singh et al., 2012). However, administration of insulin at nanomolar concentrations by activating the PI3-Akt pathway (Huang et al., 2005; Singh et al., 2012) increases neurite outgrowth of cultured DRG neurons. Nonetheless, the neurite-outgrowth promoting action of insulin on DRG neurons involves other mechanisms as well, such as the stabilization of tubulin which is essential in neurite formation (Fernyhough et al., 1989). It has also been shown that activation by insulin of TrkA expressed by peptidergic nociceptive sensory neurons, also plays an important role in insulin's neurite outgrowth promoting effects (Geetha et al., 2013).

The view that insulin exerts trophic actions on peripheral nerves has received extensive support by recent in vivo findings which showed that systemic (Xu et al., 2004) and intrathecal (Toth et al., 2006) administration of insulin prevents degenerative changes of motor and sensory fibres 
after axonal injuries. Grote and his colleagues have demonstrated that DRG neurons and peripheral nerves are insulin responsive in vivo (Grote et al., 2013). Considering the potent neurotrophic qualities of insulin on sensory nerves, in recent years several studies have focused on its possible role in the pathogenesis of diabetic neuropathy as well. It has been demonstrated that insulin signalling in DRG neurons from diabetic mice shows similarities to insulin resistance related to muscle and adipose tissues (Grote et al., 2011).

Collectively, available experimental data indicate that neural actions of insulin are mediated by multiple signalling pathways involved in various physiological and pathophysiological processes. Importantly, the possible role of insulin in the modulation of (patho)physiological processes affecting somatosensory mechanisms, in particular those implicated in the mediation of pain, has been well established.

The expression patterns of the TRPV1 and the InsR in small-sized DRG neurons have been revealed in immunohistochemical studies (Ahluwalia et al., 2000; Sugimoto et al., 2002). Further, it has been hypothesized that insulin may modulate the opening of the TRPV1 ion channel. Sathianatan and his colleagues observed that administration of insulin induces cobaltuptake of small-medium sized DRG neurons in a concentration-dependent manner, and coapplication of capsaicin with insulin potentiates the capsaicin-evoked cobalt-labelling of DRG neurons (Sathianathan et al., 2003). Similarities of the signalling pathways of the InsR and the TRPV1 have also been revealed (Heidenreich et al., 1990; Kayali et al., 1998; Cesare et al., 1999). Hence, the insulin-induced activation of DRG neurons is significantly reduced by the tyrosine kinase inhibitor, tyrphostin and the PLC inhibitor, neomycin, and by TRPV1 antagonists (Sathianathan et al., 2003). It has been revealed that about $30 \%$ of DRG neurons co-express the InsR and the TRPV1. Further experiments revealed that insulin enhances TRPV1-mediated membrane currents of cultured DRG neurons by triggering the PI3K and PKC pathways, resulting in sensitization of TRPV1 (Van Buren et al., 2005). Lilja and his colleagues also demonstrated that long-term insulin exposure increases TRPV1 protein expression by regulating the PI3K and MAPK/ERK signalling pathways (Lilja et al., 2007).

These findings have received extensive support by in vitro immunohistochemical findings. Baiou and his colleagues showed that InsR-immunoreactive (IR) mouse DRG neurons are small-medium sized, which are considered as nociceptive neurons, and display a relatively high co-expression with TRPV1, CGRP and IB4 (Baiou et al., 2007). Our recent observations 
supported these findings, by showing that InsR is co-localized with TRPV1, CGRP and IB4 in cultured adult rat DRG neurons (Lázár et al., 2018).

1.3. The role of nociceptive primary sensory nerves in pathological conditions

In the last few decades, the participation of the TRPV1-expressing nociceptive somatic and visceral PSNs has been demonstrated in a variety of physiological and pathological processes. Extensive work has been done on the role of TRPV1-expressing chemosensitive PSNs in mechanisms of pain and inflammation. Importantly, it has been recognized that chemosensitive PSNs participate not only in mechanisms of physiological (nociceptive) and pathological (neuropathic) pain but are also implicated in a variety of physiological processes including inter alia vascular reactions, smooth muscle contraction/relaxation, cardiac function, glandular secretion, and endocrine regulation (Holzer, 1988; Maggi and Meli, 1988). Pharmacological, neurochemical and immunohistochemical studies have revealed that many of these sensoryefferent or local regulatory functions of chemosensitive PSNs are mediated by neuropeptides released from the stimulated sensory nerve endings. Hence, the dual functional character of chemosensitive PSNs, first envisaged and proved by N. Jancsó (Jancsó, 1960; Jancsó et al., 1968) has been amply confirmed and supported by a vast body of experimental data (for reviews see Holzer, 1988; Maggi and Meli, 1988; Szolcsányi, 1996; Nagy et al., 2004; Jancsó et al., 2009).

It is beyond the scope of this Thesis to give an even superficial account on the role of chemosensitive PSNs in the function of different tissues and organs. However, a brief survey of the most important functional features of chemosensitive PSNs innervating some somatic and visceral organs/tissues seems to be appropriate in order to understand the similarities and dissimilarities of the morpho-functional traits of PSNs innervating the different organs.

TRPV1-expressing cutaneous sensory fibres have a pivotal role in the pathologies related to the skin. The epidermis is almost exclusively innervated by capsaicin-sensitive TRPV1-expressing, in part peptidergic sensory nerves. Hence, perineural application of capsaicin almost completely eliminated both chemical pain sensation and the fine intraepidermal nerve fibres in the rat skin. It has been shown that perineural capsaicin treatment resulted in a loss of about $80 \%$ of epidermal and about 30\% of all cutaneous sensory fibres (Jancsó and Lawson, 1990; Pini et al., 1990; Dux and Jancsó, 1994). Besides nociception, these sensory nerves, by releasing sensory 
neuropeptides, are key players of inflammatory changes, including both neurogenic and nonneurogenic inflammatory processes (Jancsó, 1960; Jancsó et al., 1980, 1985).

The significant contribution of TRPV1-immunopositive sensory fibres to the development of urinary bladder dysfunction is well-established. Classical hodological studies have revealed that the urinary bladder is innervated by capsaicin-sensitive sensory nerves from $T h_{13}-\mathrm{L}_{3}$ and $\mathrm{L}_{6}-\mathrm{S}_{1}$ DRGs, and capsaicin-sensitive urinary bladder primary afferents terminate in laminae I, V and X (Jancsó and Maggi, 1987; Gabella and Davis, 1998). The TRPV1-expression of epithelial and urothelial cells of the bladder has also been revealed in the rat (Birder et al., 2001; Avelino et al., 2002) and in man (Lazzeri et al., 2004) as well. The contribution of capsaicin-sensitive sensory nerves in the inflammatory changes of the urinary bladder has been reported decades ago (Maggi et al., 1993). Direct and indirect activation of TRPV1-expressing bladder afferents have been implicated in the mechanisms of the micturition reflex (Quartara and Maggi, 1998; Birder et al., 2001). Furthermore, activation/sensitisation of TRPV1 plays an important role in the development of urinary bladder disorders including acute cystitis, painful bladder syndrome and overactive bladder (Avelino and Cruz, 2006). Recent findings have also revealed that intravesical administration of TRPV1 agonists capsaicin or RTX increases bladder capacity of the chronically inflamed rat bladder suggesting a significant role of chemosensitive afferents in bladder pain and inflammation (Dinis et al., 2004a). Although the roles of the TRPV1expressing nerves and the endogenous ligands of the TRPV1 receptor are not fully understand in bladder dysfunctions, intravesical administration of TRPV1 agonists proved to be therapeutically beneficial in various pathologies of the urinary tract (Maggi et al., 1993; Yiangou et al., 2001).

Chemosensitive afferent nerves also play an important role in gastrointestinal physiology and pathology. Motility, secretion, endocrine and immune functions are all affected by extrinsic nerves of the gastrointestinal tract, which are comprised to a significant extent of chemosensitive afferent nerves (cf. Barthó and Szolcsányi, 1978; Barthó et al., 2004, 2008).

Retrograde labelling studies by Sharkey and his colleagues (Sharkey et al., 1984) provided evidence for the innervation of the pancreas by capsaicin-sensitive peptidergic PSNs. Sharkey and his colleagues by using retrograde tracing technique and immunohistochemistry have revealed that rat pancreas is innervated by capsaicin-sensitive sensory neurons from the $\mathrm{Th}_{6}-\mathrm{L}_{2}$ DRGs and the nodose ganglia (NGs). After neonatal capsaicin treatment, SP-IR fibres innervated the rat pancreas is also depleted (Sharkey and Williams, 1983; Sharkey et al., 1984). 
These findings have been supported by W. L. Neuhuber who described that vagal afferent fibres exclusively innervate the islets of Langerhans in rats by using anterograde tracing method (Neuhuber, 1989).

In the recent years, several studies have suggested that neurogenic inflammation mediated by peptidergic TRPV1-positive nociceptive PSNs plays an important role in the pathogenesis of acute and chronic pancreatitis. Nathan and his colleagues have demonstrated that TRPV1 antagonist, capsazepine reduces the level of neurokinin-1 receptor (NK1R), the receptor of SP, the pancreatic enzymes associated with pancreatitis and the severity of histological changes of pancreas during caerulein-induced experimental pancreatitis in mice. Furthermore, it has also been revealed that rat pancreatic acini are innervated by TRPV1-immunopositive sensory fibres which contain SP and CGRP. Other studies have showed that mRNA expression of TRPV1 is increased in rat thoracic DRG neurons after trinitrobenzene sulfonic acid induced chronic pancreatitis.

TRPV1 is also expressed in islets of Langerhans, and it has been demonstrated that TRPV1 modulates the insulin secretion of the beta cells (Akiba et al., 2004). The direct effect of sensory neuropeptides on beta cells has also been shown (Hermansen and Ahren, 1990; Barakat et al., 1994; Ahren, 2000; Razavi et al., 2006). Razavi and his colleagues have revealed that by using immunohistochemistry, islets of Langerhans are innervated by a meshwork of TRPV1-positive fibres, and these fibres are eliminated by neonatal capsaicin treatment in non-obese diabetic (NOD) mice, an experimental model of type 1 diabetes mellitus. Other working groups have showed that CGRP-expressing fibres which innervate the rat islets of Langerhans also express the TRPV1. Systemic administration of capsaicin prevents the development of glucose tolerance and hyperinsulinemia in Zucker diabetic fatty (ZDF) rats, an animal model of human type 2 diabetes (Gram et al., 2007). Additionally, the contribution of TRPV1-positive C-fibres in pancreatic tumour development has also been shown (Hartel 2006, Saloman, 2016).

1.4. Retrograde axonal tract tracing methods for the identification of primary sensory neurons innervating specific organs

Although identification of PSNs innervating different organs/tissues has some morphological, histological and functional difficulties, axonal tract tracing of neuronal pathways introduced in the early 1970's allows a precise identification of sensory and motor circuits. 
Axonal transport is essential in the intraneuronal movement of a variety of substances such as synaptic vesicles, membranous organelles, lipids, proteins and bacterial toxins. The axonal transport is crucial in the communication between the perikarya and the nerve ending. This process is regulated by cytoskeletal components of the axon including neurotubuli and motor proteins (kinesin, dynein). There are two types of axonal transport processes: anterograde or cellulifugal transport directed from the cell body to the nerve terminals, and retrograde or cellulipetal transport directed from the nerve terminals towards the cell body. Over the past few decades, neuroanatomical tract tracing methods based on axonal transport of various tracers have led to the identification of PSNs which innervate specific organs/tissues. Injection of specific tracer molecules into the selected tissues/organs allows the identification of the parent cell bodies of PSNs innervating the selected tissue/organ. Identified PSNs may be further characterized by determining their size and chemical phenotypes using morphometric, histochemical and immunohistochemical techniques.

Horseradish peroxidise (HRP) is a widely used non-selective retrograde tracer for the identification of different (unmyelinated and myelinated) types of PSNs (Molander and Grant, 1985, 1987). HRP is a non-selective tracer, hence, HRP is unsuitable for the selective identification of different sub-classes of PSNs. However, HRP conjugated with specific lectins, such as wheat germ agglutinin (WGA) or with cholera toxin B subunit is specifically taken up and transported by unmyelinated and myelinated afferent axons resulting specific labelling of the different populations of DRG.

Distinct sub-classes of PSNs express glycoconjugates with specific carbohydrate epitopes which show affinity for lectins. Small-medium sized capsaicin-sensitive DRG neurons show reactivity for specific lectins. For example, the lectin, WGA specifically binds to N-acetyl glucosamine residues of the carbohydrate chains of glycoconjugates of the plasma membrane (Sharon and Lis, 1972; Macsween and Fox, 1975). Available literature data unequivocally indicate that WGA is a specific lectin bound by small-medium sized nociceptive PSNs (Robertson and Arvidsson, 1985; Robertson, 1990; Oszlács et al., 2015). However, for the use of lectins as retrograde tracers, it is indispensable to conjugate them to specific tracers. It has been revealed that injection of WGA conjugated with biotin, fluorophore or HRP into peripheral organs results in a selective labelling of unmyelinated small-medium sized nociceptive PSNs (LaMotte and Campbell, 1978; Robertson and Arvidsson, 1985; Robertson, 1990). Therefore, in the present study WGA conjugated with biotin was used for the retrograde labelling of Cfibre PSNs innervating the targeted organs. 


\section{AIMS OF THE STUDY}

Previous observations demonstrated a functional interaction between the InsR and the TRPV1 in vitro, and a substantial co-localization of the InsR with the TRPV1 in rat and mouse native dorsal root ganglion (DRG) neurons. Although these studies have provided clear evidence for the localization and functionality of the InsR in PSNs, information is not available as to the target specificity of InsR-positive PSNs. The exploration of the target organs innervated by PSNs which express the InsR is of critical importance for the understanding of the possible role of the InsR in the mechanism of physiological and pathological processes.

Therefore, the principal aim of the present Thesis was the morphometric and neurochemical characterization of InsR-expressing nociceptive PSNs innervating somatic (skin and skeletal muscle) and visceral (pancreas and urinary bladder) organs with particular emphasis on the colocalization of the InsR with TRPV1 by using retrograde neuronal tracing techniques combined with quantitative morphometry and immunohistochemistry.

Recent observations indicated that an interplay among insulin, the sensory neuropeptides SP and CGRP and pancreatic PSNs which express the nociceptive ion channel TRPV1 may significantly contribute to pathological processes affecting both the exocrine and the endocrine pancreas. Therefore, an additional aim of the present Thesis was the further phenotypic characterization of pancreatic nociceptive DRG and NG neurons by using quantitative morphometric and immunohistochemical techniques to demonstrate the expression and coexpression patterns of the InsR, TRPV1, SP and CGRP. 


\section{MATERIALS AND METHODS}

\subsection{Experimental animals}

Adult male Wistar rats $(\mathrm{n}=17)$ weighing 300-350 g were used in this study. All experiments were approved by the Ethics Committee for Animal Care at the University of Szeged and were carried out in full accordance with the Directive 2010/63/EU of the European Parliament and of the Council on the Protection of Animals Used for Scientific Purposes and the guidelines of the Committee for Research. All efforts were made to minimize animal suffering. The number of experimental animals was kept as low as possible.

\subsection{Surgery and retrograde neuronal labelling}

The rats were anesthetized with chloral hydrate $(400 \mathrm{mg} / \mathrm{kg}$, intraperitoneally; Reanal, Budapest, Hungary) or with isoflurane (Forene ${ }^{\mathrm{TM}}$, AbbVie Hungary Ltd., Budapest, Hungary). For the identification of spinal cutaneous, muscle, urinary bladder, and spinal and vagal pancreatic PSNs, biotin-conjugated wheat germ agglutinin (bWGA; Sigma-Aldrich, Gillingham, UK, $1 \%$ in distilled water) was injected into the target organ using a Hamilton microsyringe. To identify cutaneous PSNs, $2 \times 2 \mu$ s of the bWGA solution were injected into the dorsal hind paw skin. For labelling of muscle spinal PSNs, the gastrocnemius muscle was exposed through an incision at the dorsal aspect of the calf and $2 \times 2 \mu 1 \mathrm{~s}$ of the bWGA solution were injected into the muscle. To label PSNs innervating the urinary bladder or the pancreas, the abdominal cavity was opened through a midline incision, the organs to be injected were carefully exposed and $4 \times 2 \mu$ ls of the bWGA solution were injected into the wall of the urinary bladder or the head, the body and the tail of the pancreas. Thereafter, the exposed areas were thoroughly rinsed with saline and the abdominal wall was closed in layers. After recovery from anaesthesia, the rats were returned to the animal house.

\subsection{Histological methods}

\subsubsection{Tissue preparation and sectioning}

Three days after the injection of bWGA, the rats were terminally anesthetized with an overdose of thiopental sodium (Insera Arzneimittel GmbH, Freiburg, Germany; $150 \mathrm{mg} / \mathrm{kg}$ i.p.) and were perfused transcardially first with physiological saline $(100 \mathrm{ml})$, immediately followed by a fixative containing $4 \%$ paraformaldehyde in $0.1 \mathrm{M}$ phosphate buffer ( $\mathrm{pH} 7.4)$. To examine 
neurons retrogradely labelled from the dorsal hind paw skin, the gastrocnemius muscle, the urinary bladder and the pancreas, the $\mathrm{L}_{3}-\mathrm{L}_{5}$ (Gamse et al., 1982; Swett et al., 1991), $\mathrm{L}_{4-5}$ (Peyronnard et al., 1986; Swett et al., 1991), L3-S (Jancsó and Maggi, 1987) and Th10-13 (Won et al., 1998; Takamido et al., 2006) DRGs, respectively were removed on both sides. In the case of the pancreas, the right and left NGs were also removed. The samples were post-fixed for $2 \mathrm{~h}$ and stored in $0.1 \mathrm{M}$ phosphate buffer $(\mathrm{pH} 7.4)$ containing $30 \%$ sucrose at $4{ }^{\circ} \mathrm{C}$ until sectioning. Serial frozen sections of the DRGs and the NGs, $15 \mu \mathrm{m}$ in thickness, were cut on a cryostat.

\subsubsection{Lectin- and immunohistochemistry}

Sections were rinsed twice for 10 minutes in phosphate-buffered $(0.01 \mathrm{M})$ isotonic $\mathrm{NaCl}$ solution (phosphate-buffered saline, PBS), and incubated in PBS containing 1\% donkey serum and $0.1 \%$ Triton $\mathrm{X}-100$ for 12 hours and processed for staining with the indirect immunofluorescence technique using the following antibodies: rabbit anti-InsR $\alpha$ subunit antibody (Santa Cruz Biotechnologies, Dallas, Tex., USA; 1:500, ), guinea pig anti-TRPV1 antibody (Neuromics, Edina, Minn., USA; 1:1500), mouse anti-CGRP antibody (Abcam, Cambridge, UK; 1:1500), and guinea pig anti-SP antibody (Abcam, 1:1500). Donkey antirabbit IgG labelled with DL488 (1:500), donkey anti-guinea pig IgG labelled with Cy3 (1:500) and donkey anti-mouse IgG labelled with Cy3 (1:500) were used as secondary antibodies (all from Jackson Immunoresearch Laboratories, West Grove, Pa., USA). bWGA lectin was detected by using an extravidine-AMCA conjugate (Jackson Immunoresearch Laboratories).

All antibodies were diluted in PBS containing 0.3\% Triton-X-100. Sections were incubated in the presence of the primary antibodies overnight at $4^{\circ} \mathrm{C}$ and, after washing with PBS for $3 \times 10$ min, incubated for 2 hours with the secondary antibodies. Control procedures for immunolabelling were performed by replacing the primary antisera with normal donkey serum. No immunostaining was observed in control experiments. For fluorescence microscopy, the specimens were covered with Prolong Gold antifade mounting medium (Invitrogen, Carlsbad, Calif., USA).

\subsection{Data analysis}

DRG and NG neurons with clear-cut nuclei were selected and analysed in systemic random serial photomicrographs taken with a Leica DMLB fluorescence microscope (Wetzlar, Germany) under x40 magnification, equipped with a Retiga 2000R digital camera (QImaging, Surrey, B.C., Canada) connected to a computer running the ImagePro Plus 6 analysis software 
(Media Cybernetics, Inc.; Rockville, Md., USA). Random serial images were captured from each selected sections of the ganglia.

bWGA-positive neurons with visible nuclei were selected and analysis of retrogradely labelled neurons was performed by using the ImageJ (NIH; Bethesda, Md., USA; IJ1.46r) image analysis software. The mean cross-sectional areas of the total and the labelled populations were determined. Size-frequency distribution histograms were created by using the ImageJ (NIH) software.

The relative proportions of the retrogradely labelled and InsR-, TRPV1-, CGRP- or SP-IR DRG and NG neurons were calculated in each ganglion, and pie charts and tables were generated. All data are presented as mean \pm standard deviation (SD). Statistical comparisons of the data were performed using the Fisher's exact probability test utilizing the Dell Statistica software (Dell Inc.; Tulsa, Okla., USA). A $p$ value of $\leq 0.05$ was considered as a statistically significant difference between groups. 


\section{RESULTS}

4.1. Retrograde labelling of DRG and NG neurons innervating somatic (skin, muscle) and visceral (urinary bladder, pancreas) organs

After the injection of retrograde tracer into the target organs, the tracer is rapidly taken up and transported centripetally within a few hours to the parent cell bodies of PSNs. In this study, by using bWGA as a retrograde tracer, we identified numerous PSNs in the DRGs and NGs relating to the injected organ. Our findings showed that PSNs retrogradely labelled with bWGA belonged to the small to medium sized populations of DRG and NG neurons.

Injection of bWGA into the dorsal hind paw skin resulted in the labelling of numerous neurons in the $\mathrm{L}_{3}-\mathrm{L}_{5}$ DRGs with a peak at $\mathrm{L}_{4}$ DRGs on both sides. 147 DRG neurons innervating the dorsal hind paw skin were identified and analysed from three animals. Fig. 1A illustrates retrogradely labelled cutaneous DRG neurons in the left $\mathrm{L}_{4}$ DRG. Analysis of size-frequency distribution histograms revealed that the mean cross-sectional area of the retrogradely labelled neurons amounted to $311.1 \pm 43.4 \mu \mathrm{m}^{2}$ (Fig. 2A).

Quantitative analysis revealed that after the injection of bWGA into the gastrocnemius muscle, 138 neurons were retrogradely labelled in the $\mathrm{L}_{4-5}$ DRGs with a peak at $\mathrm{L}_{5}$ DRGs on both sides from three animals. Photomicrograph in Fig. 1B illustrates neurons in the right $\mathrm{L}_{4} \mathrm{DRG}$ retrogradely labelled with bWGA from the gastrocnemius muscle. The mean cross-sectional area of the retrogradely labelled DRG neurons amounted to $345.8 \pm 55.9 \mu \mathrm{m}^{2}$ (Fig. 2B).

Injection of the retrograde tracer, bWGA into the wall of the urinary bladder resulted in the labelling of a great number of neurons in the $\mathrm{L}_{3}-\mathrm{S}_{1}$ DRGs with a peak at $\mathrm{L}_{6}$ DRGs on both sides (Fig. 1C). We identified and analysed 225 retrogradely labelled DRG neurons from four animals. Quantitative morphometry revealed that the mean cross-sectional area of the retrogradely labelled DRG neurons amounted to $339.2 \pm 54.8 \mu \mathrm{m}^{2}$ (Fig. 2C).

The DRG and NG neurons innervating the pancreas were identified by multiple injections of bWGA into the head, body and tail of the pancreas. Numerous retrogradely labelled neurons were found in the Th $9-\mathrm{L}_{1}$ DRGs on both sides with a peak in $\mathrm{Th}_{11}$, and in the left and right NGs. Fig. 1D and E illustrate pancreatic retrogradely labelled DRG (Fig. 1D) and NG (Fig. 1E) neurons in the left $\mathrm{Th}_{11}$ DRG and the right NG. Quantitative analysis revealed that 263 and 167 neurons were retrogradely labelled with bWGA in the DRGs and NGs from four animals. The 
analysis of the size frequency distribution of the retrogradely labelled DRG and NG neurons revealed that these neurons are small to medium sized with mean cross-sectional areas of 447.2 $\pm 39.4 \mu \mathrm{m}^{2}$ and 585.4 $\pm 44.9 \mu \mathrm{m}^{2}$, respectively (Fig. 2D, E).
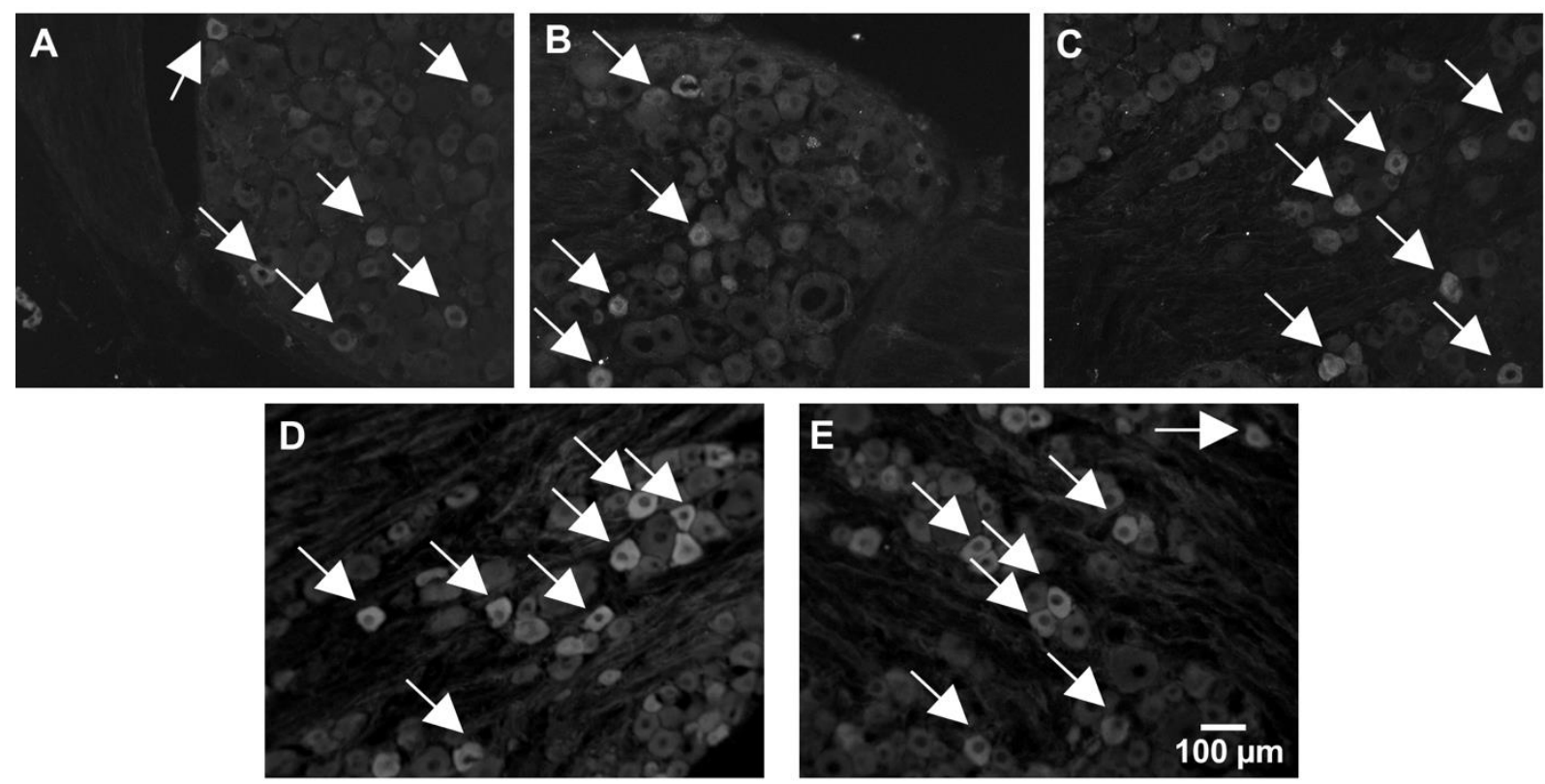

Figure 1. Photomicrographs illustrating retrogradely labelled DRG and NG neurons after injections of bWGA into the skin, the gastrocnemius muscle, the urinary bladder and the pancreas. DRG neurons innervating the dorsal hind paw skin (A), the gastrocnemius muscle (B), the urinary bladder (C) and the pancreas (D, E) show bWGA-labelling in the $\mathrm{L}_{4}(\mathrm{~A})$, the $\mathrm{L}_{5}(\mathrm{~B})$, the $\mathrm{L}_{6}(\mathrm{C})$, the $\mathrm{Th}_{11}$ (D) DRGs and in the right NG(E). The scale bar indicates $100 \mu \mathrm{m}$ and applies to all photomicrographs.

\subsection{Expression of TRPV1 in identified somatic and visceral primary sensory neurons}

The large majority of bWGA-labelled cutaneous, muscle, urinary bladder and pancreatic DRG and pancreatic NG neurons showed TRPV1 immunoreactivity. Fig. 3. illustrates retrogradely labelled DRG and NG neurons which are IR for TRPV1.

In the DRGs, $63.1 \pm 3.4 \% 62.5 \pm 2.7 \%, 65.0 \pm 1.8 \%$ and $68.2 \pm 4.8 \%$ of the retrogradely labelled neurons innervating the dorsal hind paw skin, the gastrocnemius muscle, the urinary bladder and the pancreas displayed TRPV1 immunoreactivity (Fig. 4). In the NGs, $64.0 \pm 3.9 \%$ of the identified pancreatic neurons showed TRPV1 immunopositivity (Fig. 4). 
A

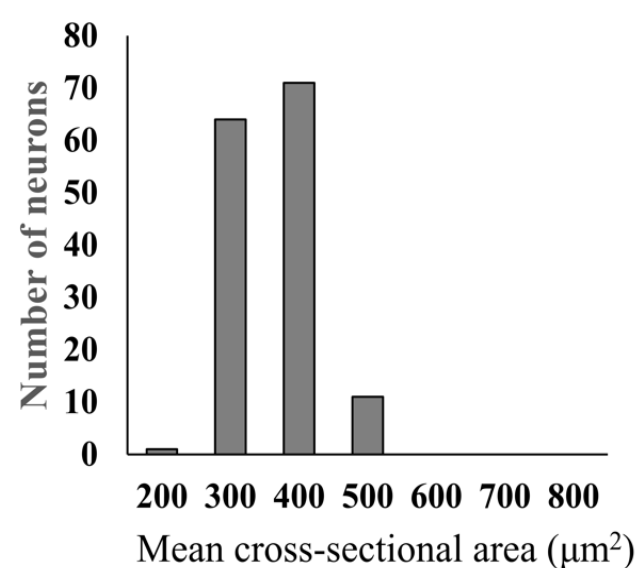

C
B

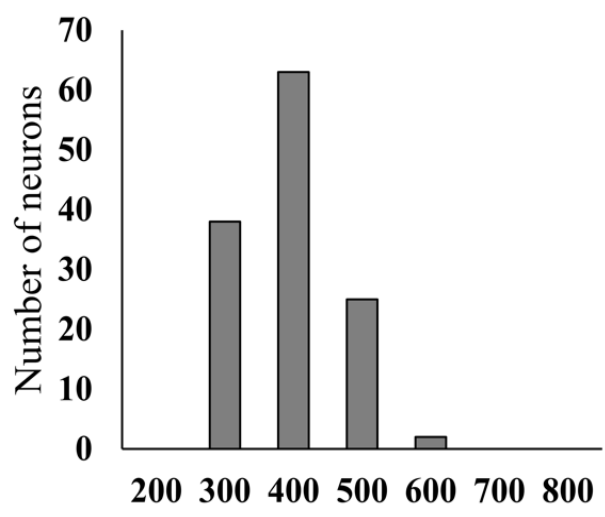

Mean cross-sectional area $\left(\mu \mathrm{m}^{2}\right)$

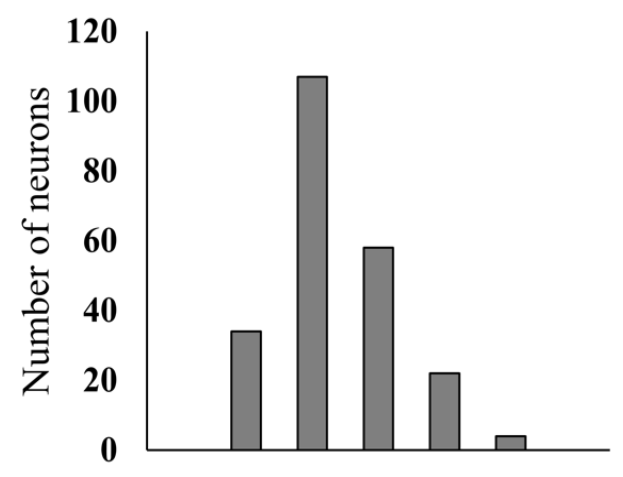

200300400500600700800

Mean cross-sectional area $\left(\mu \mathrm{m}^{2}\right.$

D

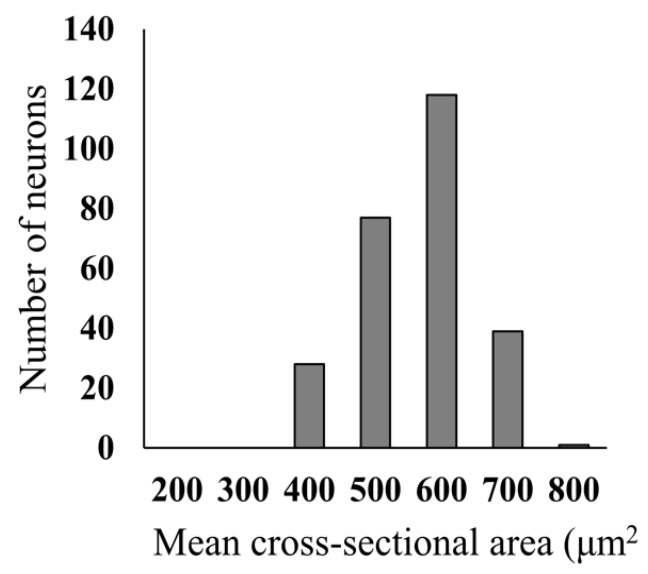

E

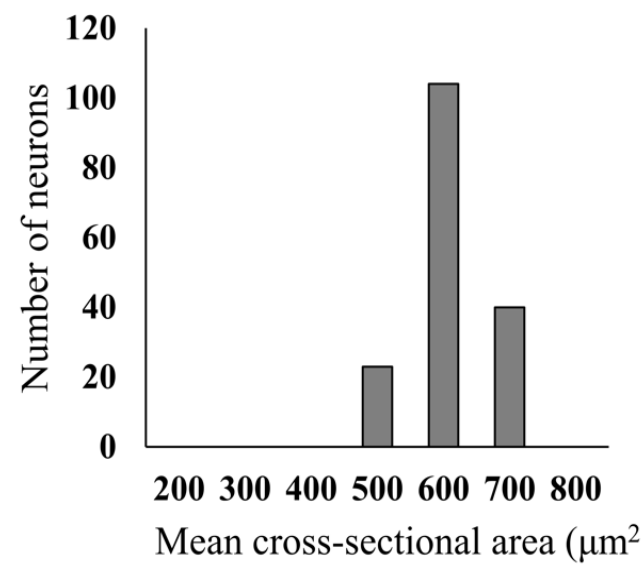

Figure 2. Size-frequency distribution histograms of dorsal root ganglion and nodose ganglion neurons retrogradely labelled with biotin-conjugated wheat germ agglutinin from the dorsal hind paw skin (A), the gastrocnemius muscle (B), the urinary bladder (C) and the pancreas (D, E). 

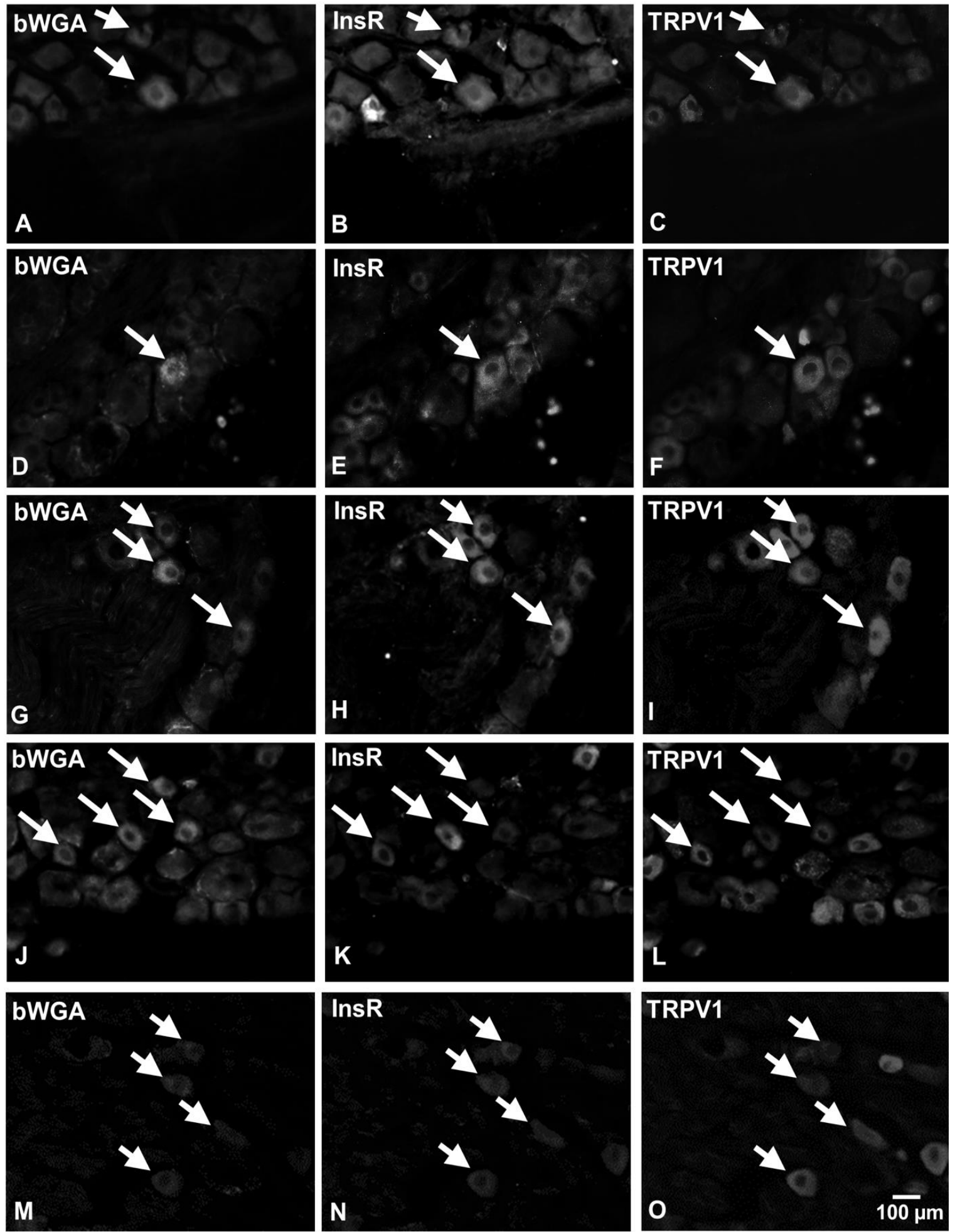

Figure 3. Photomicrographs illustrating retrogradely labelled DRG and NG neurons after injections of bWGA into the skin, the gastrocnemius muscle, the urinary bladder and the pancreas, which display immunoreactivities for the InsR and the TRPV1. bWGA-labelled DRG and NG neurons innervating the dorsal hind paw skin (A, B, C), the gastrocnemius muscle $(\mathrm{D}, \mathrm{E}, \mathrm{F})$, the urinary bladder $(\mathrm{G}, \mathrm{H}, \mathrm{I})$ and the pancreas $(\mathrm{J}, \mathrm{K}, \mathrm{L}, \mathrm{M}, \mathrm{N}, \mathrm{O})$ showing 
immunoreactivities for the InsR and the TRPV1 in the $\mathrm{L}_{4}(\mathrm{~A}, \mathrm{~B}, \mathrm{C})$, the $\mathrm{L}_{5}(\mathrm{D}, \mathrm{E}, \mathrm{F})$, the $\mathrm{L}_{6}(\mathrm{E}$, $\mathrm{F}, \mathrm{G})$, the $\mathrm{Th}_{11}(\mathrm{~J}, \mathrm{~K}, \mathrm{~L}) \mathrm{DRG}$ and in the left NG (M, N, O). The scale bar indicates $100 \mu \mathrm{m}$ and applies to all photomicrographs.

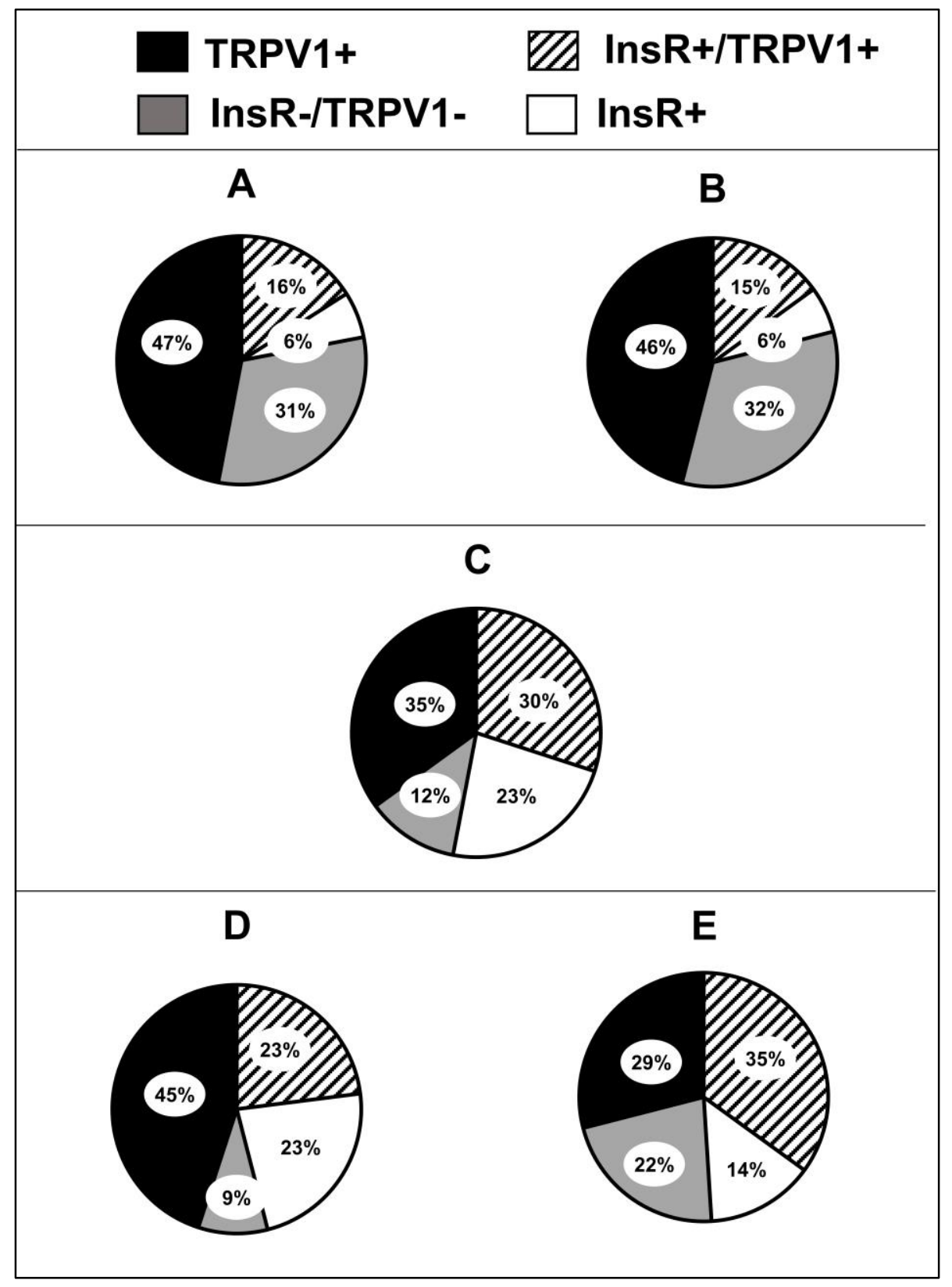

Figure 4. Pie charts show the relative proportions of the InsR- and the TRPV1-IR subpopulations of bWGA retrogradely labelled somatic and visceral DRG and NG neurons. Pie charts showing the percentage distributions and overlaps of bWGA-labelled InsRand TRPV1-immunopositive DRG and NG neurons innervating the dorsal hind paw skin (A), the gastrocnemius muscle (B), the urinary bladder (C) and the pancreas (DRG 4D, NG 4E). 
4.3. InsR expression in retrogradely labelled dorsal root ganglion and nodose ganglion neurons innervating the skin, skeletal muscle, the pancreas and the urinary bladder

A relatively high proportion of DRG neurons labelled retrogradely with bWGA innervating the dorsal hind paw skin, the gastrocnemius muscle, the urinary bladder and the pancreas displayed InsR immunostaining. Similarly, many retrogradely labelled pancreatic NG neurons showed InsR immunoreactivity. These immunohistochemical findings are illustrated in Fig. 3.

Our quantitative data indicate that $22.4 \pm 2.8 \%$ of cutaneous, $21.8 \pm 1.9 \%$ of muscle, $53.4 \pm 3.1 \%$ of urinary bladder, $48.3 \pm 2.6 \%$ of pancreatic DRG and $49.1 \pm 2.5 \%$ of pancreatic NG neurons displayed InsR immunoreactivity (Fig. 4). The statistical analysis revealed that there were no significant differences in the proportions of the InsR-IR neurons either between cutaneous and muscle DRG neurons or between pancreatic and urinary bladder spinal afferents. However, a highly significant difference between the proportions of the InsR-IR somatic and visceral DRG neurons was revealed $(\mathrm{p}<0.05)$.

4.4. Co-localization of the InsR with the TRPV1 in retrogradely labelled somatic and visceral dorsal root ganglion and nodose ganglion neurons

To reveal the co-localization of the InsR with the TRPV1, the co-expression of the InsR and the TRPV1 in the bWGA-labelled DRG and NG neuron populations, the expression of the TRPV1 in the InsR-immunopositive bWGA-labelled DRG and NG neuron populations and the expression of the InsR in the TRPV1-immunopositive bWGA-labelled DRG and NG neuron populations were examined. The co-localization patterns of the InsR and the TRPV1 in retrogradely labelled DRG and NG neurons are illustrated in Fig. 3.

First, the co-localization of the InsR with the TRPV1 was analysed in retrogradely labelled DRG and NG neurons. Our data indicated that $16.56 \pm 0.6 \%$ of cutaneous, $15.33 \pm 1.1 \%$ of muscle, $30.34 \pm 2.1 \pm \%$ of urinary bladder, $23.2 \pm 2.2 \%$ of pancreatic DRG and $35.3 \pm 1.7$ of pancreatic NG neurons displayed both InsR and TRPV1 immunoreactivity, respectively (Fig. 4). The statistical analysis revealed that there were no significant differences between either the cutaneous and muscle or the urinary bladder and pancreatic DRG and NG neurons. However, there were significant differences in the proportions of the InsR- and TRPV1-IR neurons between the somatic and visceral PSNs ( $\mathrm{p}<0.05)$. 
The proportions of the TRPV1-immunopositive neurons in the bWGA-labelled InsR-IR neuron population were also assessed. $72.7 \pm 3.4 \%, 73.3 \pm 2.6 \%, 57.1 \pm 3.6 \%$, and $50.1 \pm 3.0 \%$ of the bWGA-labelled InsR-IR DRG neurons innervating the dorsal hind paw skin, the gastrocnemius muscle, the urinary bladder and the pancreas displayed TRPV1 immunoreactivity, respectively (Table 1). Furthermore, our data indicate that $71.0 \pm 5.0 \%$ of the bWGA-labelled InsR-IR pancreatic NG neurons showed TRPV1-immunoreactivity. The statistical analysis revealed that there were no significant differences in TRPV1 expression among the five different populations of neurons.

The expression of the InsR in the retrogradely labelled TRPV1-immunopositive DRG and NG neuron populations was also revealed. In the DRGs, $25.8 \pm 2.2 \%, 25.5 \pm 2.4 \%, 43.9 \pm 2.3 \%$ and $34.0 \pm 1.96 \%$ of the bWGA-labelled TRPV1-IR neurons innervating the dorsal hind paw skin, the gastrocnemius muscle, the urinary bladder and the pancreas showed InsRimmunoreactivity, respectively (Table 2). Of the bWGA retrogradely labelled TRPV1-IR pancreatic NG neurons, $55.4 \pm 2.0 \%$ showed InsR immunoreactivity. The statistical analysis revealed that there were no significant differences in the proportions of the InsR-IR neurons between either the cutaneous and the muscle DRG neurons or between the pancreatic DRG and NG and the urinary bladder DRG neurons. However, the differences between the cutaneous and pancreatic DRG neurons, the cutaneous and bladder DRG neurons, the muscle and pancreatic DRG neurons and the muscle and urinary bladder DRG neurons were significant $(\mathrm{p}<0.05)$. 
Table 1. Proportions of InsR-IR retrogradely labelled cutaneous, muscle, urinary bladder and pancreatic DRG and pancreatic NG neurons which express the TRPV1.

\begin{tabular}{|c|c|}
\hline Target organ (origin) & TRPV1 $^{+}$neurons (\%) \\
\hline dorsal hind paw skin (DRG) & $72.7 \pm 3.4$ \\
\hline gastrocnemius muscle (DRG) & $73.3 \pm 2.6$ \\
\hline urinary bladder (DRG) & $57.1 \pm 3.6$ \\
\hline pancreas (DRG) & $50.1 \pm 3.0$ \\
\hline pancreas (NG) & $71.0 \pm 5.0$ \\
\hline
\end{tabular}

Table 2. Proportions of TRPV1-IR retrogradely labelled cutaneous, muscle, urinary bladder and pancreatic DRG and pancreatic NG neurons which express the InsR.

\begin{tabular}{|c|c|}
\hline Target organ (origin) & InsR $^{+}$neurons (\%) \\
\hline dorsal hind paw skin (DRG) & $25.8 \pm 2.2$ \\
\hline gastrocnemius muscle (DRG) & $25.5 \pm 2.4$ \\
\hline urinary bladder (DRG) & $43.9 \pm 2.3$ \\
\hline pancreas (DRG) & $34.0 \pm 1.96$ \\
\hline pancreas (NG) & $55.4 \pm 2.0$ \\
\hline
\end{tabular}


4.5. Co-localization of the InsR with sensory neuropeptides (substance $P$ and calcitonin generelated peptide) in pancreatic dorsal root ganglion and nodose ganglion neurons

Considering the importance of sensory neuropeptides and the possible role of insulin and the InsR in pathologies of the pancreas, the co-localization patterns of the InsR, CGRP and SP, were analysed in pancreatic DRG and NG neurons. Examples of the co-localization pattern of the InsR with SP and CGRP are illustrated in Fig. 5.

Our data revealed that $33.2 \pm 3.7 \%$ and $54.3 \pm 4.4 \%$ of retrogradely labelled DRG neurons innervating the pancreas displayed SP and CGRP immunoreactivity. In the NGs, $40.0 \pm 2.1 \%$ and $25.1 \pm 2.9 \%$ of retrogradely labelled pancreatic neurons showed SP and CGRP immunoreactivity (Fig. 6).

In the DRGs and the NG $14.4 \pm 1.2 \%$ and $24.2 \pm 1.0 \%$ of retrogradely labelled neurons showed InsR and SP co-localization (Fig. 6). Further, $28.4 \pm 1.3 \%$ and $46.2 \pm 1.9 \%$ of the retrogradely labelled pancreatic InsR-immunopositive DRG and NG neurons displayed SP immunoreactivity (Table 3). Conversely, $42.0 \pm 4.8 \%$ and $60.2 \pm 4.2 \%$ of the labelled SP-IR DRG and NG neurons were IR for the InsR (Table 4).

The co-localization of the InsR with CGRP was also examined. Our data revealed that $28.4 \pm 2.7 \%$ and $8.0 \pm 0.9 \%$ of the retrogradely labelled pancreatic DRG and NG neurons exhibited both InsR and CGRP immunoreactivity (Fig. 6). Further, of the retrogradely labelled InsR-immunopositive DRG and NG neurons, $58.3 \pm 5.3 \%$ and $17.4 \pm 3.6 \%$ displayed CGRP immunoreactivity (Table 3). Conversely, $52.1 \pm 4.4 \%$ and $32.0 \pm 2.5 \%$ of the retrogradely labelled pancreatic CGRP-IR DRG and NG neurons showed InsR immunopositivity (Table 5). 


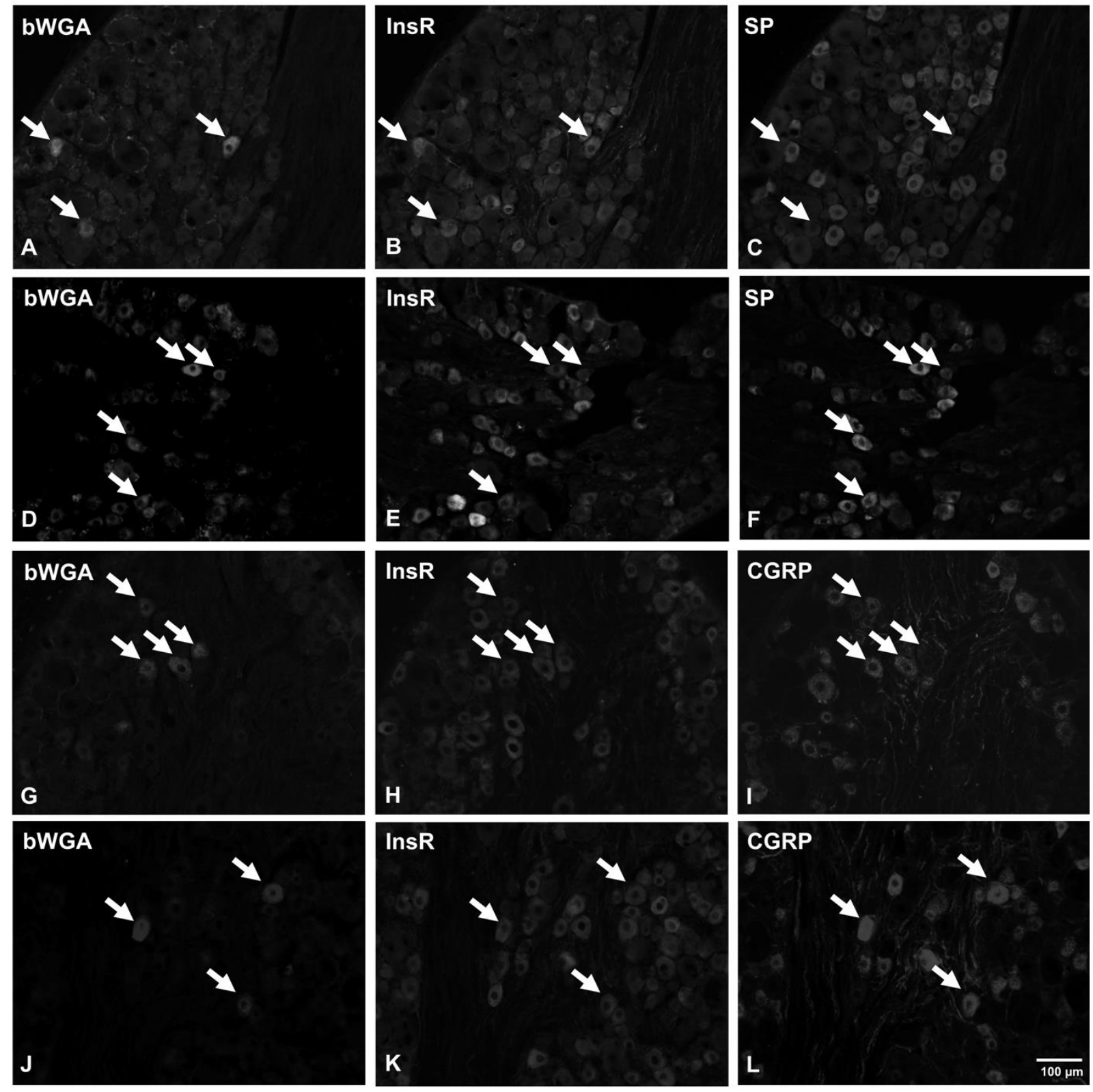

Figure 5. Photomicrographs showing bWGA-containing retrogradely labelled pancreatic DRG and NG neurons which display immunoreactivities for the InsR, SP and CGRP. bWGA-labelled DRG and NG neurons innervating the pancreas show co-localizations of the InsR with SP (A, B, C, D, E, F) or CGRP (G, H, I, J, K, L) in the Th ${ }_{10}$ DRG (A, B, C; G, H, I) and in the right NG (D, E, F; J, K, L). The scale bar indicates $100 \mu \mathrm{m}$ and applies to all photomicrographs. 


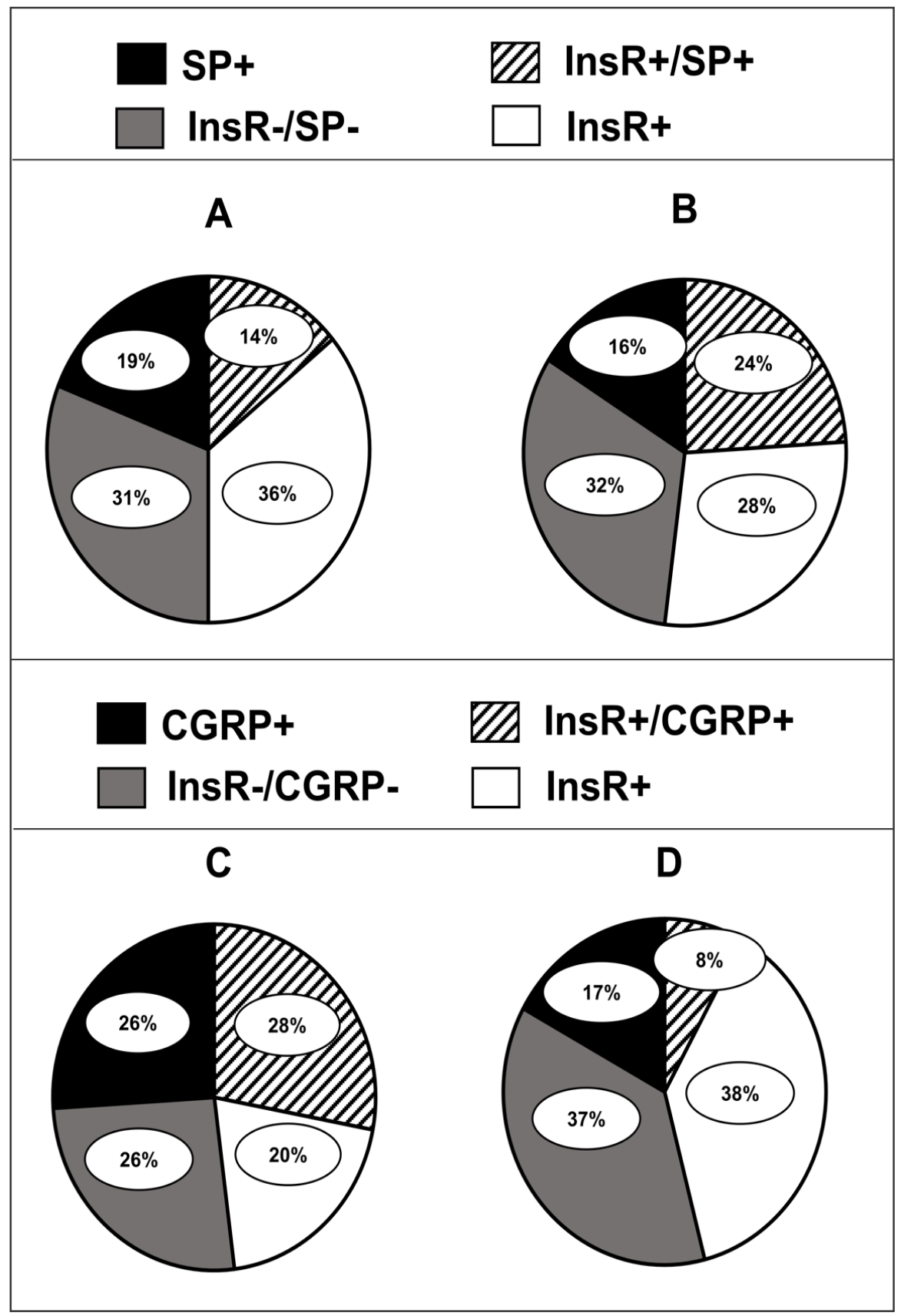

Figure 6. Pie charts show the relative proportions of the InsR- and SP- or CGRP-IR subpopulations of bWGA retrogradely labelled pancreatic DRG and NG neurons. Pie charts showing the percentage distributions and overlaps of bWGA-labelled InsR-, SP- and CGRP-immunopositive DRG (A, C) and NG (B, D) neurons innervating the pancreas. 
Table 3. Proportions of bWGA retrogradely labelled InsR-IR pancreatic DRG and NG neurons showing CGRP and SP immunoreactivity.

\begin{tabular}{|c|c|c|}
\hline Target organ (origin) & CGRP $^{+}$neurons (\%) & SP $^{+}$neurons (\%) \\
\hline pancreas (DRG) & $58.3 \pm 5.3$ & $28.4 \pm 1.3$ \\
\hline pancreas (NG) & $17.4 \pm 3.6$ & $46.2 \pm 1.9$ \\
\hline
\end{tabular}

Table 4. Proportions of SP-IR retrogradely labelled pancreatic DRG and NG neurons showing InsR immunoreactivity.

\begin{tabular}{|c|c|}
\hline Target organ (origin) & InsR $^{+}$neurons (\%) \\
\hline pancreas (DRG) & $42.0 \pm 4.8$ \\
\hline pancreas (NG) & $60.2 \pm 4.2$ \\
\hline
\end{tabular}

Table 5. Proportions of CGRP-IR retrogradely labelled pancreatic DRG and NG neurons showing InsR immunoreactivity.

\begin{tabular}{|c|c|}
\hline Target organ (origin) & InsR $^{+}$neurons (\%) \\
\hline pancreas (DRG) & $52.1 \pm 4.4$ \\
\hline pancreas (NG) & $32.0 \pm 2.5$ \\
\hline
\end{tabular}




\section{DISCUSSION}

Neurochemical characterization of neuron populations is a critical adjunct for the understanding of their function. Knowledge of the molecular traits of nerve cells, in particular PSNs of the somato-visceral system, is indispensable in deciphering of and to specifically interfere with their function. Exploring molecular similarities and dissimilarities among populations of PSNs promotes the understanding of their physiology and pathology, and provides clues for their perturbations by e.g., pharmacological means. A prominent example of this approach is the utilization of capsaicin's neuroexcitatory/neurotoxic propensity in the identification of the first nociceptive ion channel, termed the capsaicin receptor or the TRPV1 (Caterina et al., 1997).

Studies conducted in the past two decades have revealed that TRPV1 is the archetypal nociceptive ion channel functioning as a molecular integrator of noxious stimuli (Nagy et al., 2004; Gold and Caterina, 2007; Julius, 2013). Henceforth, any new information as regards the neurochemical features of TRPV1-expressing PSNs may point to novel ways to interfere with TRPV1 function including the transmission of painful stimuli and local modulation of organ functions.

PSNs belong to the best characterized nerve cell populations of the mammalian nervous system. Although a great number of neuron specific proteins, enzymes, peptides, amino acids and lectin binding sites were demonstrated in these neurons, it is generally accepted that nociceptive PSNs comprise two major subpopulations: the peptidergic and the non-peptidergic populations. It should, however, be noted that this classification is somewhat (over)simplified, since in many investigations (e.g., Winter et al., 1988; Lindsay et al., 1989), including also our own studies (Sántha et al., 2010; Lázár et al., 2018), a moderate but significant overlap has been noted between these two populations. Importantly, some specific proteins, such as the TRPV1 receptor is expressed in both the peptidergic and the non-peptidergic populations of the nociceptive PSNs.

Neurotrophins such as NGF and GDNF significantly contribute to the development, differentiation and functional characteristics of peptidergic and non-peptidergic nociceptive PSNs. In the last few decades, several studies have revealed that insulin has also a potent neurotrophic effect on cultured DRG neurons and sensory nerves as well (Recio-Pinto et al., 1986b; Fernyhough et al., 1993; Ozkul et al., 2001; Toth et al., 2006; Lázár et al., 2018). It has also been demonstrated that insulin exerts its neural actions through the InsR. Further, 
electrophysiological studies have suggested a role of the InsR in the sensitization of the TRPV1 ion channel by the archetypal agonist, capsaicin (Sathianathan et al., 2003). In addition, a direct effect of insulin on TRPV1 activation was also suggested (Sathianathan et al., 2003). Additionally, other findings have revealed that besides sensitization of the TRPV1, insulin increases the expression of the TRPV1 protein, too (Lilja et al., 2007).

Recently, the expression of the InsR has also been demonstrated in both the peptidergic and the non-peptidergic populations of rodent PSNs, many of which express the TRPV1 (Sugimoto et al., 2000, 2002; Baiou et al., 2007; Lázár et al., 2018). It has been further revealed that the InsR is expressed in DRG neurons of unidentified target innervation territories (Baiou et al., 2007; Lázár et al., 2018). Although the presence of the InsR was demonstrated in spinal PSNs, possible differences in the expression of the InsR in neurons innervating somatic or visceral organs was not investigated. Therefore, the primary aim of the experiments summarized in this Thesis was to examine the expression of the InsR in target identified somatic and visceral PSNs with respect to their possible functional implications.

First, retrogradely labelled somatic and visceral PSNs identified by retrograde axonal labelling were characterized utilizing lectin- and immunohistochemical as well as quantitative morphological techniques. Second, labelled pancreatic spinal and vagal PSNs were characterized, since PSNs have been shown to be significantly involved in the modulation or even initiation of inflammatory processes in both the exocrine and the endocrine pancreas.

Our findings confirm previous findings which demonstrated that a significant proportion of rat PSNs express the InsR (Sathianathan et al., 2003; Baiou et al., 2007; Lázár et al., 2018). Importantly, the present experiments revealed a preponderance of InsR expression in visceral PSNs as compared to somatic PSNs, suggesting that PSNs innervating visceral organs may be more sensitive to the neuromodulatory effects of insulin. Hence, our findings revealed that onehalf of urinary bladder and pancreatic sensory afferent neurons, whereas only one-quarter of cutaneous and muscle PSNs expressed the InsR.

Recent immunohistochemical studies have also revealed that InsR-expressing mouse DRG neurons are peripherin-immunopositive and belong to the small sized population of PSNs (Baiou et al., 2007). Baiou and his colleagues have also demonstrated that significant proportions of InsR-immunopositive mouse DRG neurons express TRPV1, CGRP or bind IB4 (Baiou et al., 2007). Our findings corroborate and extend previous in vitro observations and, 
regarding the cell size and the TRPV1-expression pattern of target identified InsR-expressing PSNs, suggest that these neurons are nociceptive in character.

Further, analysis of the TPRV1-immunopositivity of identified InsR-expressing PSNs revealed that about two-third of the bWGA-labelled InsR-immunopositive DRG and NG neurons innervating the dorsal hind paw skin, the gastrocnemius muscle, the urinary bladder and the pancreas express the TRPV1. Hence, in this respect a significant difference between somatic and visceral PSNs was not detected. Nonetheless, these findings suggest that a functional interaction between the TRPV1 and the InsR may bear of important functional significance predominantly in nociceptive PSNs innervating visceral tissues. Earlier studies have also suggested that interactions among insulin, the InsR and the TRPV1 expressed in PSNs may contribute to pathophysiological processes including, for example, inflammatory changes of the skin (Gamse et al., 1987; Santicioli et al., 1987), the dura mater (Dux et al., 2007) and the exocrine and endocrine pancreas (Nathan et al., 2001; Razavi et al., 2006; Gram et al., 2007; Tsui et al., 2007). The expression of the InsR and the co-expression of the InsR with the TRPV1 may also bear of important pathophysiological significance under conditions of unbalanced plasma insulin level.

In PSNs retrogradely labelled from the skin and muscle only about one-fifth of the neurons displayed InsR-immunoreactivity. The possible functional significance of InsRs and insulin in these organs is at present unclear. In earlier studies a marked reduction in cutaneous neurogenic plasma extravasation has been demonstrated in streptozotocin diabetic rats. Moreover, decreased axon reflex flare reaction was observed in diabetic patients with small fibre neuropathy (Kramer et al., 2004). Examination of the axon reflex flare response is a reliable measure of cutaneous nociceptor function in both man (Jancsó and Janka, 1981) and experimental animals (Barthó et al., 1992). Although the role of the InsR has not been considered in this process, subsequent studies showed that local application of insulin was able to ameliorate the functional deficits of cutaneous sensory nerves in diabetic patients (Kramer et al., 2004). Similarly, administration of insulin has been shown to restore impaired meningeal sensory neurogenic vasodilatatory responses in diabetic rats (Dux et al., 2007). Hence, insulin and InsRs, which is expressed in sensory nerves may contribute to mechanisms involved in the maintenance of the functional integrity of cutaneous nerves and, consequently, the skin.

Capsaicin-sensitive afferents in the skeletal muscle are essentially involved in local vascular and vasomotor reflex responses associated with exercise or chemical stimulation of C-fibres 
(Kaufman et al., 1982; Mense, 2008). Although many muscle C-fibre afferents are sensitive to capsaicin, knowledge on the chemical phenotype of muscle PSNs is modest. Considering the available experimental data, it may be assumed that insulin may modulate muscle vasodilatatory and nociceptive responses through muscle PSNs which express the TRPV1 and the InsR, as shown in the present study.

One of the most important finding of the present experiments was the observation that visceral PSNs innervating the urinary bladder and the pancreas exhibit a preponderance for the expression of the InsR as compared with somatic PSNs. It has been revealed that the damage of visceral sensory nerves innervating the urinary bladder wall may be involved in the development of cystopathies (Dinis et al., 2004b; Charrua et al., 2007), especially which are associated with diabetes mellitus and are characterized by increased post voiding residual volumes, enhanced bladder capacity and decreased bladder sensation. (Kebapci et al., 2007). This assumption is supported by observations of increased bladder capacity and disturbances in urinary bladder reflexes and micturition after neonatal capsaicin treatment which produces a selective loss of nociceptive C-fibre PSNs (Jancsó et al., 1977; Jancsó and Maggi, 1987). Recent findings have revealed that SP and CGRP receptor antagonists, by preventing the release of neuropeptides from capsaicin-sensitive afferent nerves, may specifically ameliorate inflammatory changes, such as leukocyte rolling and adhesion in the urinary bladder (Jaromi et al., 2018). Our findings by showing that about one-half of TRPV1-IR DRG neurons innervating the urinary bladder express the InsR, suggest a possible modulatory influence of insulin on urinary bladder sensory nerves and, consequently, on bladder functioning under pathological conditions. Further, regarding the role of nociceptive sensory nerves in the development of bladder pathologies, it can be hypothesized that the interaction among insulin, the InsR and the TRPV1 may contribute to the development of cystopathies associated with diabetes mellitus.

Previously, several studies suggested that TRPV1-expressing sensory neurons contribute to the development of inflammatory processes of both the exocrine and the endocrine pancreas (Nathan et al., 2001, 2002; Razavi et al., 2006; Wick et al., 2006; Iwasaki et al., 2013; Schwartz et al., 2013). Morphological studies have revealed that a significant proportion of sensory nerves innervating the pancreas are capsaicin-sensitive (Sharkey and Williams, 1983; Sharkey et al., 1984). Our findings confirm these observations by showing that up to $60 \%$ of identified small to medium sized pancreatic PSNs in both the thoracolumbar DRGs and the NGs displayed TRPV1 immunoreactivity. 
Early studies on the possible role of nociceptive sensory neurons in inflammatory processes of the exocrine pancreas have focused on the effects of capsaicin treatment. It has been revealed that neonatal capsaicin treatment significantly diminished the tissue levels of biochemical markers and histological changes associated with experimental acute pancreatitis induced by caerulein and common pancreaticobiliary duct ligation (Nathan et al., 2002). Further, it has been demonstrated that L-arginine-induced necrotizing pancreatitis increased the number of spinal neurons expressing c-fos, a marker of neuronal activation, in Rexed's laminae I and II of the spinal dorsal horn, a major site of the central termination of nociceptive PSNs which express the TRPV1 (Wick et al., 2006). Other studies have showed that mRNA expression of TRPV1 is increased in rat thoracic DRG neurons after trinitrobenzene sulfonic acid induced chronic pancreatitis (Xu et al., 2007). Schwartz and his colleagues have also demonstrated that continuous treatment of experimental acute pancreatitis with a TRPV1 antagonist reduced pancreatic inflammation and histological alterations. Accordingly, these observations suggested that early administration of TRPV1 antagonists may decrease the possibility of the development of chronic pancreatitis (Schwartz et al., 2013).

Similarly, the role of nociceptive PSNs in the development of inflammation in the endocrine pancreas has also been raised. Razavi and his colleagues have demonstrated that TRPV1positive sensory nerve fibres are important elements of the initiation and progression of type 1 diabetes mellitus through interfering with local immune and inflammatory processes. They have revealed that in NOD mice pre-treatment with capsaicin delayed the onset of diabetes, and reduced its incidence compared to control NOD mice (Razavi et al., 2006).

In addition, the contribution of TRPV1-positive C-fibres in pancreatic tumour development has also been shown. mRNA level of TRPV1 is significantly increased in human ductal pancreatic adenocarcinoma compared with control. In vitro, RTX alone or in combination with chemotherapeutic agents decelerate tumour cell proliferation in pancreatic cancer cell lines (Hartel et al., 2006). Ablation of C-fibres by capsaicin treatment slows the progression of ductal pancreatic adenocarcinoma in transgenic mice (Saloman et al., 2016).

The activation of TRPV1 results in the release of pro-inflammatory neuropeptides, such as SP and CGRP. In recent years, several studies have demonstrated that rat pancreatic acini and islets of Langerhans are innervated by TRPV1-immunopositive sensory fibres which contain CGRP and SP suggesting a possible role of sensory neuropeptides in the inflammatory processes of both the exocrine and the endocrine pancreas. It has been revealed that injection of capsaicin 
into the pancreaticobiliary duct induces endocytosis of the NK1R in laminae I-III of the thoracic dorsal horn of the rat spinal cord. Moreover, in control NOD mice lower TRPV1 protein expression was observed. Further, depressed level of TRPV1-mediated responses such as the release of SP was also demonstrated (Razavi et al., 2006). In particular, it has been suggested that sensory neuropeptides such as SP and CGRP prevent diabetic changes in pancreas (Khachatryan et al., 1997; Razavi et al., 2006).

Our findings strongly support the observations suggesting a crucial role of TRPV1-positive PSNs in the development of pathologies of the pancreas, including acute and chronic pancreatitis, diabetes mellitus and tumour development.

Our quantitative data by demonstrating that one-half and one-quarter of identified pancreatic DRG and NG neurons contain CGRP, whereas, more than one-quarter and one-half show SP immunoreactivity, provide morphological basis to these findings. Nonetheless, the most important finding of the present experiments is the demonstration of InsRs in pancreatic spinal and vagal sensory ganglion neurons and its co-localization with the TRPV1, SP and CGRP. In the present study, we detected for the first time the presence of InsR in identified pancreatic afferent neurons. InsR-immunoreactivity was demonstrated in similar proportions of the retrogradely labelled DRG and NG neurons. Our data also demonstrated the co-localization of the TRPV1 and the InsR in identified pancreatic PSNs. Indeed, our findings also show that relatively high proportions of InsR-IR DRG and NG neurons display SP and CGRP immunoreactivities. Conversely, one-half of the CGRP-immunopositive and up to one-quarter of the SP-IR DRG and NG neurons display InsR-immunoreactivity.

Previously, interactions among insulin, the InsRs and nociceptive TPRV1-IR sensory fibres in the initiation of pancreatitis and the development of diabetes mellitus have been suggested. This is supported by the findings showing that, in the rat, the pancreatic parenchyma, including the islets of Langerhans and pancreatic acini, is exposed to very high levels of insulin during the secretory process of the hormone (Bendayan, 1993). Insulin, by reaching sensory nerves, which have been demonstrated in the immediate surroundings of the islet apparatus (Razavi et al., 2006; Gram et al., 2007; Tsui et al., 2007; Iwasaki et al., 2013), and also in the exocrine pancreas (Wick et al., 2006; Liddle, 2007; Schneider et al., 2009; Schwartz et al., 2013), may trigger the release of inflammatory neuropeptides either directly by activation of neural TRPV1, or indirectly, through the modulation of TRPV1 channel opening. Considering the modulating role of InsRs on capsaicin-induced activation of TRPV1, it is assumed that activation of neural 
TRPV1 by insulin through the release of proinflammatory neuropeptides such as CGRP and SP may contribute to the formation of a vicious cycle resulting in an exaggeration of pancreatic inflammatory processes. 


\section{CONCLUSIONS}

The studies presented of this Thesis was revealed the morphometric and neurochemical characteristics of InsR-expressing PSNs innervating somatic and visceral organs. In particular, the phenotypic characterization of pancreatic nociceptive DRG and NG neurons was assessed in detail.

Previously, several studies have suggested that insulin can modulate the activation of nociceptive PSNs. The importance of the interaction among insulin, InsR and TRPV1 in this process has also been indicated. However, data were lacking on the expression of InsR and its co-localization with TRPV1 in PSNs innervating different organs. In the experiments summarized in this Thesis, we demonstrated, for the first time, the presence of InsRs in retrogradely labelled cutaneous, muscle, urinary bladder and pancreatic primary sensory neurons. We demonstrated that a high proportion of small to medium sized InsR-expressing PSNs display TRPV1-immunoreactivity for these InsR-positive DRG and NG neurons are nociceptive in character. Moreover, our quantitative immunohistochemical data revealed a preponderance of InsR-immunoreactivity among PSNs which innervate visceral organs. These findings suggest that visceral PSNs are more likely to be exposed to the modulatory effects of insulin on sensory functions, including neurotrophic, nociceptive and inflammatory processes. Considering the newly found co-localization of the InsR with the TRPV1 in identified visceral DRG and NG neurons and the functional interplay between these receptors, a significant role of InsR-expressing visceral PSNs in the development of visceral inflammatory processes could be hypothesized.

In the recent years, several studies have suggested that peptidergic TRPV1-expressing sensory nerves have a role in the development of pancreatic pathologies. Further, it has also been demonstrated that an interaction between insulin and the pancreatic nociceptive afferent nerves may be contributing to pathological processes affecting both the exocrine and the endocrine pancreas. Our quantitative data provide morphological basis for possible functional interactions among the nociceptive ion channel TRPV1, the InsR, and the proinflammatory neuropeptides SP and CGRP expressed by pancreatic DRG and NG neurons. Based on these observations, a new, proinflammatory role of insulin in the pathomechanism of pancreatic pathologies may emerge. 


\section{SUMMARY}

Over the past few decades, several studies have demonstrated that insulin, apart from being a pivotal regulator of carbohydrate metabolism, is significantly involved in various neuronal processes such as neural survival, initiation of neurite outgrowth and regulation of neuronal activity. It has also been revealed that neural effects of insulin are mediated by the InsR, which has been demonstrated in the nerve tissue, too. In addition, experiments on cultured rat PSNs demonstrated that insulin may sensitize the nociceptive ion channel, the TRPV1 by increasing the activation of this channel by capsaicin. TRPV1-expressing PSNs comprise over $90 \%$ of Cfibre ganglion cells and are involved in pain sensation and implicated in neurogenic inflammatory responses through the release of sensory neuropeptides such as CGRP and SP. Further, it has been suggested that interaction among insulin, the InsR and the TRPV1 expressed in PSNs may contribute to physiological and pathophysiological processes in various organs. Immunohistochemical studies provided further support to this notion by showing a substantial co-localization of the TRPV1 and the InsR in rat and mouse PSNs of unidentified target innervation territories. The expression of the InsR in nociceptive sensory nerves of different organs and tissues may bear of particular interest as regards the modulatory influence of insulin on a variety of tissue processes. Hence, exploring the localization of the InsR in PSNs serving different organs is of critical importance for the further understanding of the role of these particular afferent nerves in physiological and pathological processes.

Therefore, the aim of the present experiments summarized in this Thesis was to reveal, by using hodological and immunohistochemical methods, the expression of the InsR in rat cutaneous, muscle, pancreatic and urinary bladder spinal and vagal afferent neurons and its co-localization with the TRPV1. Further, considering the importance of nociceptive PSNs in the pathologies of both the exocrine and endocrine pancreas, we evaluated morphometric and neurochemical properties of identified rat spinal and vagal pancreatic afferent neurons with particular emphasis on the co-localization of the InsR with SP and CGRP.

Our results indicate that almost one-half of the visceral and less than one-quarter of somatic PSNs express the InsR. A great majority of these neurons exhibits TRPV1 immunoreactivity. Our quantitative data also show that $\sim 15 \%$ of somatic and $\sim 30 \%$ of visceral spinal PSNs displayed InsR and TRPV1 co-localization. Additionally, co-localization of the InsR with SP or CGRP was demonstrated in pancreatic spinal and vagal neurons. 
These findings provide evidence for the co-localization of the InsR and the TRPV1 in somatic and visceral PSNs and demonstrate that a higher proportion of visceral PSNs express the InsR and display InsR-TRPV1 co-localization. Furthermore, our findings also show that a relatively high proportion of pancreatic spinal and vagal PSNs display co-localization of the TRPV1, the InsR and sensory neuropeptides. The findings suggest that insulin may modulate TRPV1 activation and subsequent peptide release from visceral afferents and contribute to nociceptive and inflammatory mechanisms of the viscera. 


\section{ACKNOWLEDGEMENTS}

I would like to thank all the people who have inspired me and helped me during my doctoral studies.

First and foremost, I would like to express my sincere gratitude to my supervisors Prof. Dr. Gábor Jancsó and Dr. Péter Sántha for the continuous support of my doctoral studies and related research, for their patience, motivation and immense knowledge.

My special thanks go to my colleagues and my friends: Dr. Zoltán Ambrus Kovács, Dr. Szatmár Horváth, Dr. Ildikó Demeter, Dr. Andor Gál, Dr. Bálint Kincses, Dr. Ádám Nagy, Dr. Bálint Andó and Dr. Bettina Kádár for their friendship, endless patience, encouragement and help. I would like to thank the colleagues of the $2^{\text {nd }}$ and $5^{\text {th }}$ ward of the Department of Psychiatry and the members of the Functional Neuromorphology Lab of the Department of Physiology for making a productive and stimulating environment to my scientific work. I would like to thank Prof. Dr. Zoltán Janka and Prof. Dr. János Kálmán, the previous and current heads of the Department of Psychiatry for encouraging my doctoral studies.

Last, but not least, my deepest thanks go to my family: my sister, my mother, my father, my grandparents and all of my friends for their continuous love and never-ending support in my life and scientific work.

I dedicate this Thesis to my grandfather: Professor Dr. György Lázár who introduced me into the scientific world. 


\section{REFERENCES}

Ahluwalia J, Urban L, Capogna M, Bevan S, Nagy I (2000) Cannabinoid 1 receptors are expressed in nociceptive primary sensory neurons. Neuroscience 100:685-688.

Ahren B (2000) Autonomic regulation of islet hormone secretion--implications for health and disease. Diabetologia 43:393-410.

Akiba Y, Kato S, Katsube K, Nakamura M, Takeuchi K, Ishii H, Hibi T (2004) Transient receptor potential vanilloid subfamily 1 expressed in pancreatic islet beta cells modulates insulin secretion in rats. Biochem Biophys Res Commun 321:219-225.

Alvarez FJ, Fyffe RE (2000) Nociceptors for the 21st century. Curr Rev Pain 4:451-458.

Amara SG, Jonas V, Rosenfeld MG, Ong ES, Evans RM (1982) Alternative RNA processing in calcitonin gene expression generates mRNAs encoding different polypeptide products. Nature 298:240-244.

Andres K (1961) Untersuchungen über den Feinbau von Spinalganglien. Z Zellforsch 55:1-48.

Avelino A, Cruz C, Nagy I, Cruz F (2002) Vanilloid receptor 1 expression in the rat urinary tract. Neuroscience 109:787-798.

Avelino A, Cruz F (2006) TRPV1 (vanilloid receptor) in the urinary tract: expression, function and clinical applications. Naunyn Schmiedebergs Arch Pharmacol 373:287-299.

Baiou D, Sántha P, Avelino A, Charrua A, Bacskai T, Matesz K, Cruz F, Nagy I (2007) Neurochemical characterization of insulin receptor-expressing primary sensory neurons in wild-type and vanilloid type 1 transient receptor potential receptor knockout mice. J Comp Neurol 503:334-347.

Banting FG, Best CH (1922) The internal secretion of the pancreas. J Lab Clin Med 7:251-266.

Barakat A, Skoglund G, Boissard C, Rosselin G, Marie JC (1994) Calcitonin gene-related peptide and islet amyloid polypeptide stimulate insulin secretion in RINm5F cells through a common receptor coupled to a generation of cAMP. Biosci Rep 14:1-13.

Barthó L, Benko R, Holzer-Petsche U, Holzer P, Undi S, Wolf M (2008) Role of extrinsic afferent neurons in gastrointestinal motility. Eur Rev Med Pharmacol Sci 12 Suppl 1:2131.

Barthó L, Benko R, Patacchini R, Petho G, Holzer-Petsche U, Holzer P, Lazar Z, Undi S, Illenyi L, Antal A, Horvath O-P (2004) Effects of capsaicin on visceral smooth muscle: a valuable tool for sensory neurotransmitter identification. Eur J Pharmacol 500:143-157.

Barthó L, Ernst R, Pierau FK, Sann H, Faulstroh K, Petho G (1992) An opioid peptide inhibits capsaicin-sensitive vasodilatation in the pig's skin. Neuropeptides 23:227-237.

Barthó L, Szolcsányi J (1978) The site of action of capsaicin on the guinea-pig isolated ileum. Naunyn Schmiedebergs Arch Pharmacol 305:75-81.

Baskin DG, Brewitt B, Davidson DA, Corp E, Paquette T, Figlewicz DP, Lewellen TK, Graham 
MK, Woods SG, Dorsa DM (1986) Quantitative autoradiographic evidence for insulin receptors in the choroid plexus of the rat brain. Diabetes 35:246-249.

Beck PW, Handwerker HO (1974) Bradykinin and serotonin effects on various types of cutaneous nerve fibers. Pflugers Arch 347:209-222.

Bendayan M (1993) Pathway of insulin in pancreatic tissue on its release by the B-cell. Am J Physiol 264:G187-94.

Bennett DL, Michael GJ, Ramachandran N, Munson JB, Averill S, Yan Q, McMahon SB, Priestley J V (1998) A distinct subgroup of small DRG cells express GDNF receptor components and GDNF is protective for these neurons after nerve injury. J Neurosci 18:3059-3072.

Bergeron JJ, Rachubinski R, Searle N, Borts D, Sikstrom R, Posner BI (1980) Polypeptide hormone receptors in vivo: demonstration of insulin binding to adrenal gland and gastrointestinal epithelium by quantitative radioautography. J Histochem Cytochem 28:824-835.

Birder LA, Kanai AJ, de Groat WC, Kiss S, Nealen ML, Burke NE, Dineley KE, Watkins S, Reynolds IJ, Caterina MJ (2001) Vanilloid receptor expression suggests a sensory role for urinary bladder epithelial cells. Proc Natl Acad Sci U S A 98:13396-13401.

Birder LA, Kullmann FA (2018) Role of neurogenic inflammation in local communication in the visceral mucosa. Semin Immunopathol 40:261-279.

Bliss M (1993) The history of insulin. Diabetes Care 16 Suppl 3:4-7.

Bonnington JK, McNaughton PA (2003) Signalling pathways involved in the sensitisation of mouse nociceptive neurones by nerve growth factor. J Physiol 551:433-446.

Bossaller C, Reither K, Hehlert-Friedrich C, Auch-Schwelk W, Graf K, Grafe M, Fleck E (1992) In vivo measurement of endothelium-dependent vasodilation with substance $P$ in man. Herz 17:284-290.

Brain SD, Williams TJ, Tippins JR, Morris HR, MacIntyre I (1985) Calcitonin gene-related peptide is a potent vasodilator. Nature 313:54-56.

Bucholz CF (1816) Chemische Untersuchung der trockenen reifen spanischen Pfeffers. Alm oder Taschenb für Scheidekünstler und Apotheker 37:1-30.

Burnham PA, Silva JA, Varon S (1974) Anabolic responses of embryonic dorsal root ganglia to nerve growth factor, insulin, concanavalin A or serum in vitro. J Neurochem 23:689695.

Caterina MJ, Schumacher MA, Tominaga M, Rosen TA, Levine JD, Julius D (1997) The capsaicin receptor: a heat-activated ion channel in the pain pathway. Nature 389:816-824.

Cesare P, Dekker L V, Sardini A, Parker PJ, McNaughton PA (1999) Specific involvement of PKC-epsilon in sensitization of the neuronal response to painful heat. Neuron 23:617624. 
Charrua A, Cruz CD, Cruz F, Avelino A (2007) Transient receptor potential vanilloid subfamily 1 is essential for the generation of noxious bladder input and bladder overactivity in cystitis. J Urol 177:1537-1541.

Chen M, Porte DJ (1976) The effect of rate and dose of glucose infusion on the acute insulin response in man. J Clin Endocrinol Metab 42:1168-1175.

Di Marzo V, Bisogno T, De Petrocellis L, Brandi I, Jefferson RG, Winckler RL, Davis JB, Dasse O, Mahadevan A, Razdan RK, Martin BR (2001) Highly selective CB(1) cannabinoid receptor ligands and novel $\mathrm{CB}(1) / \mathrm{VR}(1)$ vanilloid receptor "hybrid" ligands. Biochem Biophys Res Commun 281:444-451.

Dinis P, Charrua A, Avelino A, Cruz F (2004a) Intravesical resiniferatoxin decreases spinal cfos expression and increases bladder volume to reflex micturition in rats with chronic inflamed urinary bladders. BJU Int 94:153-157.

Dinis P, Charrua A, Avelino A, Yaqoob M, Bevan S, Nagy I, Cruz F (2004b) Anandamideevoked activation of vanilloid receptor 1 contributes to the development of bladder hyperreflexia and nociceptive transmission to spinal dorsal horn neurons in cystitis. $\mathrm{J}$ Neurosci 24:11253-11263.

Djouhri L, Lawson SN (2004) Abeta-fiber nociceptive primary afferent neurons: a review of incidence and properties in relation to other afferent A-fiber neurons in mammals. Brain Res Brain Res Rev 46:131-145.

Docherty K, Steiner DF (1982) Post-translational proteolysis in polypeptide hormone biosynthesis. Annu Rev Physiol 44:625-638.

Duggan AW, Morton CR, Zhao ZQ, Hendry IA (1987) Noxious heating of the skin releases immunoreactive substance $\mathrm{P}$ in the substantia gelatinosa of the cat: a study with antibody microprobes. Brain Res 403:345-349.

Dux M, Jancsó G (1994) A new technique for the direct demonstration of overlapping cutaneous innervation territories of peptidergic $\mathrm{C}$-fibre afferents of rat hindlimb nerves. $\mathbf{J}$ Neurosci Methods 55:47-52.

Dux M, Rosta J, Pintér S, Sántha P, Jancsó G (2007) Loss of capsaicin-induced meningeal neurogenic sensory vasodilatation in diabetic rats. Neuroscience 150:194-201.

Dux M, Sántha P, Jancsó G (2003) Capsaicin-sensitive neurogenic sensory vasodilatation in the dura mater of the rat. J Physiol 552:859-867.

Fernyhough P, Mill JF, Roberts JL, Ishii DN (1989) Stabilization of tubulin mRNAs by insulin and insulin-like growth factor I during neurite formation. Brain Res Mol Brain Res 6:109120.

Fernyhough P, Willars GB, Lindsay RM, Tomlinson DR (1993) Insulin and insulin-like growth factor I enhance regeneration in cultured adult rat sensory neurones. Brain Res 607:117124.

Furtado LM, Somwar R, Sweeney G, Niu W, Klip A (2002) Activation of the glucose transporter GLUT4 by insulin. Biochem Cell Biol 80:569-578. 
Gabella G, Davis C (1998) Distribution of afferent axons in the bladder of rats. J Neurocytol 27:141-155.

Gammeltoft S (1984) Insulin receptors: binding kinetics and structure-function relationship of insulin. Physiol Rev 64:1321-1378.

Gamse R, Holzer P, Lembeck F (1980) Decrease of substance P in primary afferent neurones and impairment of neurogenic plasma extravasation by capsaicin. Br J Pharmacol 68:207213.

Gamse R, Petsche U, Lembeck F, Jancsó G (1982) Capsaicin applied to peripheral nerve inhibits axoplasmic transport of substance P and somatostatin. Brain Res 239:447-462.

Gamse R, Posch M, Saria A, Jancsó G (1987) Several mediators appear to interact in neurogenic inflammation. Acta Physiol Hung 69:343-354.

Gasparovic I, Hadzovic S, Hukovic S, Stern P (1964) Contribution to the theory that substance $\mathrm{p}$ has a transmitter role in sensitive pathway. Med Exp Int J Exp Med 10:303-306.

Gasser HS, Erlanger J (1927) The role played by the sizes of the constitent fibers of a nerve trunk in determining the form of its action potential wave. Am J Physiol 80:522-547.

Geetha T, Rege SD, Mathews SE, Meakin SO, White MF, Babu JR (2013) Nerve growth factor receptor TrkA, a new receptor in insulin signaling pathway in PC12 cells. J Biol Chem 288:23807-23813.

Gold M, Caterina MJ (2007) Molecular Biology of the Nociceptor / Transduction. In: Handbook of the Senses (Basbaum AI, Bushnell M, eds), pp 43-73. Elsevier B.V.

Gram DX, Ahrén B, Nagy I, Olsen UB, Brand CL, Sundler F, Tabanera R, Svendsen O, Carr RD, Sántha P, Wierup N, Hansen AJ (2007) Capsaicin-sensitive sensory fibers in the islets of Langerhans contribute to defective insulin secretion in Zucker diabetic rat, an animal model for some aspects of human type 2 diabetes. Eur J Neurosci 25:213-223.

Grote CW, Morris JK, Ryals JM, Geiger PC, Wright DE (2011) Insulin receptor substrate 2 expression and involvement in neuronal insulin resistance in diabetic neuropathy. Exp Diabetes Res 2011:212571.

Grote CW, Ryals JM, Wright DE (2013) In vivo peripheral nervous system insulin signaling. J Peripher Nerv Syst 18:209-219.

Guo A, Simone DA, Stone LS, Fairbanks CA, Wang J, Elde R (2001) Developmental shift of vanilloid receptor 1 (VR1) terminals into deeper regions of the superficial dorsal horn: correlation with a shift from TrkA to Ret expression by dorsal root ganglion neurons. Eur J Neurosci 14:293-304.

Hartel M, di Mola FF, Selvaggi F, Mascetta G, Wente MN, Felix K, Giese NA, Hinz U, Di Sebastiano P, Buchler MW, Friess H (2006) Vanilloids in pancreatic cancer: potential for chemotherapy and pain management. Gut 55:519-528.

Havrankova J, Roth J, Brownstein M (1978) Insulin receptors are widely distributed in the central nervous system of the rat. Nature 272:827-829. 
Head H, Rivers WHR, Sherren J (1905) The Afferent Nervous System from a New Aspect. Brain 28:99-115.

Heidenreich KA, Toledo SP, Brunton LL, Watson MJ, Daniel-Issakani S, Strulovici B (1990) Insulin stimulates the activity of a novel protein kinase $\mathrm{C}, \mathrm{PKC}$-epsilon, in cultured fetal chick neurons. J Biol Chem 265:15076-15082.

Hermansen K, Ahren B (1990) Dual effects of calcitonin gene-related peptide on insulin secretion in the perfused dog pancreas. Regul Pept 27:149-157.

Hill JM, Lesniak MA, Pert CB, Roth J (1986) Autoradiographic localization of insulin receptors in rat brain: prominence in olfactory and limbic areas. Neuroscience 17:1127-1138.

Hogan PD (1983) Expression of markers for pain sensorys in cell culture.

Hőgyes E (1878) Adatok a paprika (Capsicum annuum) élettani hatásához. Orv Hetil 9:117130.

Hökfelt T, Kellerth JO, Nilsson G, Pernow B (1975) Substance p: localization in the central nervous system and in some primary sensory neurons. Science 190:889-890.

Holzer P (1988) Local effector functions of capsaicin-sensitive sensory nerve endings: involvement of tachykinins, calcitonin gene-related peptide and other neuropeptides. Neuroscience 24:739-768.

Holzer P (1991) Capsaicin: cellular targets, mechanisms of action, and selectivity for thin sensory neurons. Pharmacol Rev 43:143-201.

Huang T-J, Verkhratsky A, Fernyhough P (2005) Insulin enhances mitochondrial inner membrane potential and increases ATP levels through phosphoinositide 3-kinase in adult sensory neurons. Mol Cell Neurosci 28:42-54.

Hunt CC (1951) The reflex activity of mammalian small-nerve fibres. J Physiol 115:456-469.

Inomata K, Ogawa K (1981) [Oblongata in the spinal trigeminal nucleus of the adult rat (author's transl)]. No To Shinkei 33:1037-1043.

Iwasaki Y, Shimomura K, Kohno D, Dezaki K, Ayush EA, Nakabayashi H, Kubota N, Kadowaki T, Kakei M, Nakata M, Yada T (2013) Insulin Activates Vagal Afferent Neurons Including those Innervating Pancreas via Insulin Cascade and Ca2+ Influx: Its Dysfunction in IRS2-KO Mice with Hyperphagic Obesity. PLoS One 8.

Jancsó G (1992) Pathobiological reactions of C-fibre primary sensory neurones to peripheral nerve injury. Exp Physiol 77:405-431.

Jancsó G, Hökfelt T, Lundberg JM, Király E, Halász N, Nilsson G, Terenius L, Rehfeld J, Steinbusch H, Verhofstad A, Elde R, Said S, Brown M (1981) Immunohistochemical studies on the effect of capsaicin on spinal and medullary peptide and monoamine neurons using antisera to substance $\mathrm{P}$, gastrin/CCK, somatostatin, VIP, enkephalin, neurotensin and 5-hydroxytryptamine. J Neurocytol 10:963-980.

Jancsó G, Janka Z (1981) A simple test for topographical diagnosis of sensory nervous system 
lesions. Eur Neurol 20:84-87.

Jancsó G, Katona M, Horváth V, Sántha P, Nagy I (2009) Sensory nerves as modulators of cutaneous inflammatory reactions in health and disease. In: Neurogenic Inflammation in Health and Disease (Jancsó G, ed), pp 3-36. Elsevier B.V.

Jancsó G, Király E (1980) Distribution of chemosensitive primary sensory afferents in the central nervous system of the rat. J Comp Neurol 190:781-792.

Jancsó G, Király E, Jancsó-Gábor A (1977) Pharmacologically induced selective degeneration of chemosensitive primary sensory neurones. Nature 270:741-743.

Jancsó G, Király E, Jancsó-Gábor A (1980) Direct evidence for an axonal site of action of capsaicin. Naunyn Schmiedebergs Arch Pharmacol 313:91-94.

Jancsó G, Király E, Joó F, Such G, Nagy A (1985) Selective degeneration by capsaicin of a subpopulation of primary sensory neurons in the adult rat. Neurosci Lett 59:209-214.

Jancsó G, Király E, Such G, Joó F, Nagy A (1987) Neurotoxic effect of capsaicin in mammals. Acta Physiol Hung 69:295-313.

Jancsó G, Knyihar E (1975) Functional linkage between nociception and fluoride-resistant acid phosphatase activity in the Rolando substance. Neurobiology 5:42-43.

Jancsó G, Lawson SN (1990) Transganglionic degeneration of capsaicin-sensitive C-fiber primary afferent terminals. Neuroscience 39:501-511.

Jancsó G, Maggi CA (1987) Distribution of capsaicin-sensitive urinary bladder afferents in the rat spinal cord. Brain Res 418:371-376.

Jancsó G, Obál FJ, Tóth-Kása I, Katona M, Husz S (1985) The modulation of cutaneous inflammatory reactions by peptide-containing sensory nerves. Int J Tissue React 7:449457.

Jancsó G, Sávay G, Király E (1978) Appearance of histochemically detectable ionic calcium in degenerating primary sensory neurons. Acta Histochem 62:165-169.

Jancsó N (1960) Role of the nerve terminals in the mechanism of inflammatory reactions. Bull Millard Film Hosp 7:53-77.

Jancsó N (1968) Desensitization with capsaicin as a tool for studying the function of pain receptors. Pharmacol Pain.

Jancsó N, Jancsó-Gábor A, Szolcsányi J (1967) Direct evidence for neurogenic inflammation and its prevention by denervation and by pretreatment with capsaicin. Br J Pharmacol Chemother 31:138-151.

Jancsó N, Jancsó-Gábor A, Szolcsányi J (1968) The role of sensory nerve endings in neurogenic inflammation induced in human skin and in the eye and paw of the rat. Br J Pharmacol Chemother 33:32-41.

Járomi P, Garab D, Hartmann P, Bodnár D, Nyiri S, Sántha P, Boros M, Jancsó G, Szabó A 
(2018) Capsaicin-induced rapid neutrophil leukocyte activation in the rat urinary bladder microcirculatory bed. Neurourol Urodyn 37:690-698.

Johnson EM, Rich KM, Yip HK (1986) The role of NGF in sensory neurons in vivo. Trends Neurosci 9:33-37.

Ju G, Hökfelt T, Brodin E, Fahrenkrug J, Fischer JA, Frey P, Elde RP, Brown JC (1987) Primary sensory neurons of the rat showing calcitonin gene-related peptide immunoreactivity and their relation to substance P-, somatostatin-, galanin-, vasoactive intestinal polypeptideand cholecystokinin-immunoreactive ganglion cells. Cell Tissue Res 247:417-431.

Julius D (2013) TRP channels and pain. Annu Rev Cell Dev Biol 29:355-384.

Julius D, Basbaum AI (2001) Molecular mechanisms of nociception. Nature 413:203-210.

Jung J, Hwang SW, Kwak J, Lee SY, Kang CJ, Kim WB, Kim D, Oh U (1999) Capsaicin binds to the intracellular domain of the capsaicin-activated ion channel. J Neurosci 19:529-538.

Kaufman MP, Iwamoto GA, Longhurst JC, Mitchell JH (1982) Effects of capsaicin and bradykinin on afferent fibers with ending in skeletal muscle. Circ Res 50:133-139.

Kayali AG, Eichhorn J, Haruta T, Morris AJ, Nelson JG, Vollenweider P, Olefsky JM, Webster NJ (1998) Association of the insulin receptor with phospholipase C-gamma (PLCgamma) in 3T3-L1 adipocytes suggests a role for PLCgamma in metabolic signaling by insulin. $\mathbf{J}$ Biol Chem 273:13808-13818.

Kebapci N, Yenilmez A, Efe B, Entok E, Demirustu C (2007) Bladder dysfunction in type 2 diabetic patients. Neurourol Urodyn 26:814-819.

Khachatryan A, Guerder S, Palluault F, Cote G, Solimena M, Valentijn K, Millet I, Flavell RA, Vignery A (1997) Targeted expression of the neuropeptide calcitonin gene-related peptide to beta cells prevents diabetes in NOD mice. J Immunol 158:1409-1416.

Kido Y, Nakae J, Accili D (2001) Clinical review 125: The insulin receptor and its cellular targets. J Clin Endocrinol Metab 86:972-979.

Kim BM, Lee SH, Shim WS, Oh U (2004) Histamine-induced $\mathrm{Ca}(2+)$ influx via the PLA(2)/lipoxygenase/TRPV1 pathway in rat sensory neurons. Neurosci Lett 361:159162.

Knyihar-Csillik E, Bezzegh A, Boti S, Csillik B (1986) Thiamine monophosphatase: a genuine marker for transganglionic regulation of primary sensory neurons. J Histochem Cytochem 34:363-371.

Kramer HH, Schmelz M, Birklein F, Bickel A (2004) Electrically stimulated axon reflexes are diminished in diabetic small fiber neuropathies. Diabetes 53:769-774.

LaMotte RH, Campbell JN (1978) Comparison of responses of warm and nociceptive C-fiber afferents in monkey with human judgments of thermal pain. J Neurophysiol 41:509-528.

Lawson SN, Biscoe TJ (1979) Development of mouse dorsal root ganglia: an autoradiographic and quantitative study. J Neurocytol 8:265-274. 
Lawson SN, Harper AA, Harper EI, Garson JA, Anderton BH (1984) A monoclonal antibody against neurofilament protein specifically labels a subpopulation of rat sensory neurones. J Comp Neurol 228:263-272.

Lawson SN, Waddell PJ (1991) Soma neurofilament immunoreactivity is related to cell size and fibre conduction velocity in rat primary sensory neurons. J Physiol 435:41-63.

Lázár BA, Jancsó G, Pálvölgyi L, Dobos I, Nagy I, Sántha P (2018) Insulin Confers Differing Effects on Neurite Outgrowth in Separate Populations of Cultured Dorsal Root Ganglion Neurons: The Role of the Insulin Receptor. Front Neurosci 12:732.

Lazarov NE (2002) Comparative analysis of the chemical neuroanatomy of the mammalian trigeminal ganglion and mesencephalic trigeminal nucleus. Prog Neurobiol 66:19-59.

Lazzeri M, Vannucchi MG, Zardo C, Spinelli M, Beneforti P, Turini D, Faussone-Pellegrini M-S (2004) Immunohistochemical evidence of vanilloid receptor 1 in normal human urinary bladder. Eur Urol 46:792-798.

Levi-Montalcini R (1966) The nerve growth factor: its mode of action on sensory and sympathetic nerve cells. Harvey Lect 60:217-259.

Liddle RA (2007) The role of Transient Receptor Potential Vanilloid 1 (TRPV1) channels in pancreatitis. Biochim Biophys Acta 1772:869-878.

Lilja J, Laulund F, Forsby A (2007) Insulin and insulin-like growth factor type-I up-regulate the vanilloid receptor-1 (TRPV1) in stably TRPV1-expressing SH-SY5Y neuroblastoma cells. J Neurosci Res 85:1413-1419.

Lindsay RM, Lockett C, Sternberg J, Winter J (1989) Neuropeptide expression in cultures of adult sensory neurons: modulation of substance $\mathrm{P}$ and calcitonin gene-related peptide levels by nerve growth factor. Neuroscience 33:53-65.

Lloyd D (1943) Neuron patterns controlling transmission of ipsilateral hind limb reflexes in cat. J Neurophysiol 6:293-315.

Macsween JM, Fox RA (1975) Carcinoembryonic antigen: characterization of binding with insoluble lectins. Br J Cancer 31:288-292.

Maggi CA (1995) Tachykinins and calcitonin gene-related peptide (CGRP) as co-transmitters released from peripheral endings of sensory nerves. Prog Neurobiol 45:1-98.

Maggi CA, Lecci A, Santicioli P, Del Bianco E, Giuliani S (1993) Cyclophosphamide-induced cystitis in rats: involvement of capsaicin-sensitive primary afferents. Agents Actions 38 Spec No:C28-30.

Maggi CA, Meli A (1988) The sensory-efferent function of capsaicin-sensitive sensory neurons. Gen Pharmacol 19:1-43.

Marks JL, Porte DJ, Stahl WL, Baskin DG (1990) Localization of insulin receptor mRNA in rat brain by in situ hybridization. Endocrinology 127:3234-3236.

Massague J, Pilch PF, Czech MP (1980) Electrophoretic resolution of three major insulin 
receptor structures with unique subunit stoichiometries. Proc Natl Acad Sci U S A 77:7137-7141.

Mense S (2008) Muscle pain: mechanisms and clinical significance. Dtsch Arztebl Int 105:214219.

Meyer RA, Campbell JN (1981) Evidence for two distinct classes of unmyelinated nociceptive afferents in monkey. Brain Res 224:149-152.

Molander C, Grant G (1985) Cutaneous projections from the rat hindlimb foot to the substantia gelatinosa of the spinal cord studied by transganglionic transport of WGA-HRP conjugate. J Comp Neurol 237:476-484.

Molander C, Grant G (1987) Spinal cord projections from hindlimb muscle nerves in the rat studied by transganglionic transport of horseradish peroxidase, wheat germ agglutinin conjugated horseradish peroxidase, or horseradish peroxidase with dimethylsulfoxide. J Comp Neurol 260:246-255.

Molliver DC, Wright DE, Leitner ML, Parsadanian AS, Doster K, Wen D, Yan Q, Snider WD (1997) IB4-binding DRG neurons switch from NGF to GDNF dependence in early postnatal life. Neuron 19:849-861.

Montell C (2001) Physiology, phylogeny, and functions of the TRP superfamily of cation channels. Sci STKE 2001:re1.

Moriyama T, Higashi T, Togashi K, Iida T, Segi E, Sugimoto Y, Tominaga T, Narumiya S, Tominaga M (2005) Sensitization of TRPV1 by EP1 and IP reveals peripheral nociceptive mechanism of prostaglandins. Mol Pain 1:3.

Nagy I, Sántha P, Jancsó G, Urbán L (2004) The role of the vanilloid (capsaicin) receptor (TRPV1) in physiology and pathology. Eur J Pharmacol 500:351-369.

Nathan JD, Patel a a, McVey DC, Thomas JE, Prpic V, Vigna SR, Liddle R a (2001) Capsaicin vanilloid receptor-1 mediates substance $\mathrm{P}$ release in experimental pancreatitis. Am $\mathrm{J}$ Physiol Gastrointest Liver Physiol 281:G1322--8 Available at: http://www.ncbi.nlm.nih.gov/pubmed/11668042.

Nathan JD, Peng RY, Wang Y, McVey DC, Vigna SR, Liddle RA (2002) Primary sensory neurons: a common final pathway for inflammation in experimental pancreatitis in rats. Am J Physiol Gastrointest Liver Physiol 283:G938-46.

Nelson E, Dawson L (1923) Constitution of capsaicin, the pungent principle of Capsicum. III. J Am Chem Soc 45:2179-2181.

Neuhuber WL (1989) Vagal afferent fibers almost exclusively innervate islets in the rat pancreas as demonstrated by anterograde tracing. J Auton Nerv Syst 29:13-18.

Nilius B, Owsianik G (2011) The transient receptor potential family of ion channels. Genome Biol 12:218.

Oszlács O, Jancsó G, Kis G, Dux M, Sántha P (2015) Perineural capsaicin induces the uptake and transganglionic transport of choleratoxin B subunit by nociceptive C-fiber primary 
afferent neurons. Neuroscience 311:243-252.

Ozkul Y, Sabuncu T, Yazgan P, Nazligul Y (2001) Local insulin injection improves median nerve regeneration in NIDDM patients with carpal tunnel syndrome. Eur J Neurol 8:329334.

Pacold ST, Blackard WG (1979) Central nervous system insulin receptors in normal and diabetic rats. Endocrinology 105:1452-1457.

Peyronnard JM, Charron LF, Lavoie J, Messier JP (1986) Motor, sympathetic and sensory innervation of rat skeletal muscles. Brain Res 373:288-302.

Pini A, Baranowski R, Lynn B (1990) Long-Term Reduction in the Number of C-Fibre Nociceptors Following Capsaicin Treatment of a Cutaneous Nerve in Adult Rats. Eur J Neurosci 2:89-97.

Porszász J, Jancsó N (1959) Studies on the action potentials of sensory nerves in animals desensitized with capsaicine. Acta Physiol Acad Sci Hung 16:299-306.

Price J (1985) An immunohistochemical and quantitative examination of dorsal root ganglion neuronal subpopulations. J Neurosci 5:2051-2059.

Quartara L, Maggi CA (1998) The tachykinin NK1 receptor. Part II: Distribution and pathophysiological roles. Neuropeptides 32:1-49.

Raizada MK, Yang JW, Fellows RE (1980) Binding of [125I]insulin to specific receptors and stimulation of nucleotide incorporation in cells cultured from rat brain. Brain Res 200:389-400.

Razavi R, Chan Y, Afifiyan FN, Liu XJ, Wan X, Yantha J, Tsui H, Tang L, Tsai S, Santamaria P, Driver JP, Serreze D, Salter MW, Dosch HM (2006) TRPV1+ Sensory Neurons Control ?? Cell Stress and Islet Inflammation in Autoimmune Diabetes. Cell 127:11231135.

Recio-Pinto E, Ishii DN (1984) Effects of insulin, insulin-like growth factor-II and nerve growth factor on neurite outgrowth in cultured human neuroblastoma cells. Brain Res 302:323-334.

Recio-Pinto E, Lang FF, Ishii DN (1984) Insulin and insulin-like growth factor II permit nerve growth factor binding and the neurite formation response in cultured human neuroblastoma cells. Proc Natl Acad Sci U S A 81:2562-2566 Available at: http://www.pubmedcentral.nih.gov/articlerender.fcgi?artid=345103\&tool=pmcentrez\&re ndertype $=$ abstract.

Recio-Pinto E, Rechler MM, Ishii DN (1986a) Effects of insulin, insulin-like growth factor-II, and nerve growth factor on neurite formation and survival in cultured sympathetic and sensory neurons. J Neurosci 6:1211-1219.

Recio-Pinto E, Rechler MM, Ishii DN (1986b) Effects of insulin, insulin-like growth factor-II, and nerve growth factor on neurite formation and survival in cultured sympathetic and sensory neurons. J Neurosci 6:1211-1219. 
Rivers WHR, Head H (1908) A Human Experiment in Nerve Division. Brain 31:323-450.

Robertson B (1990) Wheat germ agglutinin binding in rat primary sensory neurons: a histochemical study. Histochemistry 94:81-85.

Robertson B, Arvidsson J (1985) Transganglionic transport of wheat germ agglutinin-HRP and choleragenoid-HRP in rat trigeminal primary sensory neurons. Brain Res 348:44-51.

Roger LJ, Fellows RE (1980) Stimulation of ornithine decarboxylase activity by insulin in developing rat brain. Endocrinology 106:619-625.

Saloman JL, Albers KM, Li D, Hartman DJ, Crawford HC, Muha EA, Rhim AD, Davis BM (2016) Ablation of sensory neurons in a genetic model of pancreatic ductal adenocarcinoma slows initiation and progression of cancer. Proc Natl Acad Sci U S A 113:3078-3083.

Saltiel AR, Pessin JE (2003) Insulin signaling in microdomains of the plasma membrane. Traffic 4:711-716.

Sann H, McCarthy PW, Jancsó G, Pierau FK (1995) RT97: a marker for capsaicin-insensitive sensory endings in the rat skin. Cell Tissue Res 282:155-161.

Sántha P, Oszlács O, Dux M, Dobos I, Jancsó G (2010) Inhibition of glucosylceramide synthase reversibly decreases the capsaicin-induced activation and TRPV1 expression of cultured dorsal root ganglion neurons. Pain 150:103-112.

Santicioli P, Gamse R, Maggi CA, Meli A (1987) Cystometric changes in the early phase of streptozotocin-induced diabetes in rats: evidence for sensory changes not correlated to diabetic neuropathy. Naunyn Schmiedebergs Arch Pharmacol 335:580-587.

Sathianathan V, Avelino A, Charrua A, Sántha P, Matesz K, Cruz F, Nagy I (2003) Insulin induces cobalt uptake in a subpopulation of rat cultured primary sensory neurons. Eur $\mathbf{J}$ Neurosci 18:2477-2486.

Schneider L, Hackert T, Heck M, Hartwig W, Fritz S, Strobel O, Gebhard M-M, Werner J (2009) Capsaicin reduces tissue damage in experimental acute pancreatitis. Pancreas 38:676-680.

Schwartz ES, La J-H, Scheff NN, Davis BM, Albers KM, Gebhart GF (2013) TRPV1 and TRPA1 antagonists prevent the transition of acute to chronic inflammation and pain in chronic pancreatitis. J Neurosci 33:5603-5611.

Sharkey KA, Williams RG (1983) Extrinsic innervation of the rat pancreas: demonstration of vagal sensory neurones in the rat by retrograde tracing. Neurosci Lett 42:131-135.

Sharkey KA, Williams RG, Dockray GJ (1984) Sensory substance P innervation of the stomach and pancreas. Demonstration of capsaicin-sensitive sensory neurons in the rat by combined immunohistochemistry and retrograde tracing. Gastroenterology 87:914-921.

Sharon N, Lis H (1972) Lectins: cell-agglutinating and sugar-specific proteins. Science 177:949-959. 
Sherrington CS (1906) The Integrative Action of the Nervous System.

Silos-Santiago I, Molliver DC, Ozaki S, Smeyne RJ, Fagan AM, Barbacid M, Snider WD (1995) Non-TrkA-expressing small DRG neurons are lost in TrkA deficient mice. J Neurosci 15:5929-5942.

Silverman JD, Kruger L (1988) Lectin and neuropeptide labeling of separate populations of dorsal root ganglion neurons and associated "nociceptor" thin axons in rat testis and cornea whole-mount preparations. Somatosens Res 5:259-267.

Silverman JD, Kruger L (1990) Selective neuronal glycoconjugate expression in sensory and autonomic ganglia: relation of lectin reactivity to peptide and enzyme markers. $\mathbf{J}$ Neurocytol 19:789-801.

Singh B, Xu Y, McLaughlin T, Singh V, Martinez JA, Krishnan A, Zochodne DW (2012) Resistance to trophic neurite outgrowth of sensory neurons exposed to insulin. $J$ Neurochem 121:263-276.

Snider WD, McMahon SB (1998) Tackling pain at the source: new ideas about nociceptors. Neuron 20:629-632.

Sousa-Valente J, Brain SD (2018) A historical perspective on the role of sensory nerves in neurogenic inflammation. Semin Immunopathol 40:229-236.

Sugimoto K, Murakawa Y, Sima AAF (2002) Expression and localization of insulin receptor in rat dorsal root ganglion and spinal cord. J Peripher Nerv Syst 7:44-53.

Sugimoto K, Murakawa Y, Zhang W, Xu G, Sima AA (2000) Insulin receptor in rat peripheral nerve: its localization and alternatively spliced isoforms. Diabetes Metab Res Rev 16:354363.

Swett JE, Torigoe Y, Elie VR, Bourassa CM, Miller PG (1991) Sensory neurons of the rat sciatic nerve. Exp Neurol 114:82-103.

Szállási A, Blumberg PM (1990) Resiniferatoxin and its analogs provide novel insights into the pharmacology of the vanilloid (capsaicin) receptor. Life Sci 47:1399-1408.

Szállási A, Blumberg PM, Nilsson S, Hökfelt T, Lundberg JM (1994) Visualization by $[3 \mathrm{H}]$ resiniferatoxin autoradiography of capsaicin-sensitive neurons in the rat, pig and man. Eur J Pharmacol 264:217-221.

Szolcsányi J (1996) Capsaicin-sensitive sensory nerve terminals with local and systemic efferent functions: facts and scopes of an unorthodox neuroregulatory mechanism. Prog Brain Res 113:343-359.

Takamido S, Kataoka Y, Tanano A, Cui Y, Ikeura T, Shimatani M, Kubota Y, Okazaki K, Yamada H (2006) Intrapancreatic axonal hyperbranching of dorsal root ganglia neurons in chronic pancreatitis model rats and its relation to pancreatic pain. Pancreas 33:268-279.

Tang H-B, Inoue A, Oshita K, Nakata Y (2004) Sensitization of vanilloid receptor 1 induced by bradykinin via the activation of second messenger signaling cascades in rat primary afferent neurons. Eur J Pharmacol 498:37-43. 
Taylor-Blake B, Zylka MJ (2010) Prostatic acid phosphatase is expressed in peptidergic and nonpeptidergic nociceptive neurons of mice and rats. PLoS One 5:e8674.

Tominaga M, Caterina MJ, Malmberg AB, Rosen TA, Gilbert H, Skinner K, Raumann BE, Basbaum AI, Julius D (1998) The cloned capsaicin receptor integrates multiple painproducing stimuli. Neuron 21:531-543.

Toth C, Brussee V, Martinez JA, McDonald D, Cunningham FA, Zochodne DW (2006) Rescue and regeneration of injured peripheral nerve axons by intrathecal insulin. Neuroscience 139:429-449.

Tsui H, Razavi R, Chan Y, Yantha J, Dosch HM (2007) "Sensing" autoimmunity in type 1 diabetes. Trends Mol Med 13:405-413.

Uchida K, Tominaga M (2011) The role of thermosensitive TRP (transient receptor potential) channels in insulin secretion. Endocr J 58:1021-1028.

V Euler US, Gaddum JH (1931) An unidentified depressor substance in certain tissue extracts. J Physiol 72:74-87.

Van Buren JJ, Bhat S, Rotello R, Pauza ME, Premkumar LS (2005) Sensitization and translocation of TRPV1 by insulin and IGF-I. Mol Pain 1:17.

Van Der Stelt M, Di Marzo V (2004) Endovanilloids. Putative endogenous ligands of transient receptor potential vanilloid 1 channels. Eur J Biochem 271:1827-1834.

Watanabe M, Hirose Y, Sugimoto M, Nakanishi M, Watanabe H, Shimada M (1992) The distribution of tissue insulin receptors in the mouse by whole-body autoradiography. $\mathrm{J}$ Recept Res 12:13-37.

Waters SB, Yamauchi K, Pessin JE (1995) Insulin-stimulated disassociation of the SOS-Grb2 complex. Mol Cell Biol 15:2791-2799.

Werther GA, Hogg A, Oldfield BJ, McKinley MJ, Figdor R, Allen AM, Mendelsohn FA (1987) Localization and characterization of insulin receptors in rat brain and pituitary gland using in vitro autoradiography and computerized densitometry. Endocrinology 121:1562-1570.

Whitcomb DC, O’Dorisio TM, Cataland S, Shetzline MA, Nishikawara MT (1985) Identification of tissue insulin receptors: use of a unique in vivo radioreceptor assay. Am J Physiol 249:E561-7.

White MF (2006) Regulating insulin signaling and beta-cell function through IRS proteins. Can J Physiol Pharmacol 84:725-737.

Wick EC, Hoge SG, Grahn SW, Kim E, Divino L a, Grady EF, Bunnett NW, Kirkwood KS (2006) Transient receptor potential vanilloid 1, calcitonin gene-related peptide, and substance P mediate nociception in acute pancreatitis. Am J Physiol Gastrointest Liver Physiol 290:G959--G969.

Winter J, Forbes CA, Sternberg J, Lindsay RM (1988) Nerve growth factor (NGF) regulates adult rat cultured dorsal root ganglion neuron responses to the excitotoxin capsaicin. Neuron 1:973-981. 
Won MH, Park HS, Jeong YG, Park HJ (1998) Afferent innervation of the rat pancreas: retrograde tracing and immunohistochemistry in the dorsal root ganglia. Pancreas 16:8087.

Xu G-Y, Winston JH, Shenoy M, Yin H, Pendyala S, Pasricha PJ (2007) Transient receptor potential vanilloid 1 mediates hyperalgesia and is up-regulated in rats with chronic pancreatitis. Gastroenterology 133:1282-1292.

Xu Q-G, Li X-Q, Kotecha SA, Cheng C, Sun HS, Zochodne DW (2004) Insulin as an in vivo growth factor. Exp Neurol 188:43-51.

Yiangou Y, Facer P, Ford A, Brady C, Wiseman O, Fowler CJ, Anand P (2001) Capsaicin receptor VR1 and ATP-gated ion channel P2X3 in human urinary bladder. BJU Int 87:774-779. 